\title{
Climate sensitivity and resistance under pure- and mixed-stand scenarios in Lower Austria evaluated with distributed lag models and penalized regression splines for tree-ring time series
}

\author{
Arne Nothdurft ${ }^{1}$ (D) Markus Engel $^{1}$
}

Received: 7 April 2019 / Revised: 29 August 2019 / Accepted: 14 September 2019 / Published online: 24 September 2019

(c) The Author(s) 2019

\begin{abstract}
Penalized regression splines and distributed lag models were used to evaluate the effects of species mixing on productivity and climate-related resistance via tree-ring width measurements from sample cores. Data were collected in Lower Austria from sample plots arranged in a triplet design. Triplets were established for sessile oak [Quercus petraea (Matt.) Liebl.] and Scots pine (Pinus sylvestris L.), European beech (Fagus sylvatica L.) and Norway spruce [Picea abies (L.) H. Karst.], and European beech and European larch (Larix decidua Mill.). Mixing shortened the temporal range of time-lagged climate effects for beech, spruce, and larch, but only slightly changed the effects for oak and pine. Beech and spruce as well as beech and larch exhibited contrasting climate responses, which were consequently reversed by mixing. Single-tree productivity was reduced by between $-15 \%$ and $-28 \%$ in both the mixed oak-pine and beech-spruce stands but only slightly reduced in the mixed beech-larch stands. Measures of climate sensitivity and resistance were derived by model predictions of conditional expectations for simulated climate sequences. The relative climate sensitivity was, respectively, reduced by between -16 and -39 percentage points in both the beech-spruce and beech-larch mixed stands. The relative climate sensitivity of pine increased through mixing, but remained unaffected for oak. Mixing increased the resistance in both the beech-larch and the beech-spruce mixed stand. In the mixed oak-pine stand, resistance of pine was decreased and remained unchanged for oak.
\end{abstract}

Keywords Distributed lag model $\cdot$ Climate sensitivity $\cdot$ Resistance $\cdot$ Tree-ring width $\cdot$ Species mixing

\section{Introduction}

Altered environmental conditions during the past century, expressed particularly by warmer climates and changed atmospheric depositions, have led to accelerated growth dynamics in forest ecosystems and produced overall increased growth rates (Pretzsch et al. 2014). However, recent projections of future climate conditions in the greater

Communicated by David Drew.

Electronic supplementary material The online version of this article (https://doi.org/10.1007/s10342-019-01234-x) contains supplementary material, which is available to authorized users.

Arne Nothdurft

arne.nothdurft@boku.ac.at

1 Department of Forest- and Soil Sciences, Institute of Forest Growth, University of Natural Resources and Life Sciences, Vienna (BOKU), Vienna, Austria
Alpine region suggest a higher frequency, intensity, and duration of heat waves (Beniston et al. 2007), which might be coincident with less rainfall, especially in summer months (Rajczak et al. 2013; Gobiet et al. 2014). Thus, according to predictions from regional climate models, the occurrence of longer and more severe drought periods is likely (Jacob et al. 2014). Contrary to productivity gains observed in the past, the intensification of such drought periods is likely to have negative effects on the future productivity of European forests (Lindner et al. 2010), especially because drought is the major driver of tree mortality in various forest ecosystems globally (Allen et al. 2010; Clark et al. 2016).

The formulation of appropriate silvicultural guidelines is a crucial task in light of adaptations to the possible effects of global warming on the productivity of forest ecosystems (Pretzsch and Zenner 2017). However, forestry has long rotation periods, and before guidelines can be enacted by public authorities, different candidate scenarios must be evaluated via comprehensive model simulations and with respect to the expected economic benefit as well as the required 
management effort. In doing so, growth projections should provide a realistic picture of future stand development under a changing environment. Because dynamic changes in factors other than the competitive status have so far been underrepresented in existing growth models, a further refinement of the existing empirical growth models is needed in terms of climate-sensitive parametrization (Albert and Schmidt 2010).

Additional challenges may be expected in the context of such revision work, as forest structure is likely to become more complex with respect to multi-layering and species mixing; see e.g., Ehbrecht et al. (2017) and references therein. Thus, future management strategies also have to anticipate possible risk factors associated with the expected increase in structural diversity (Knoke et al. 2008; Knoke 2017). Little is currently known about the possible effects of species diversity on the resistance and resilience of mixed stands compared with single-species stands, but mixing may significantly lower susceptibility against biotic disturbances (Bauhus et al. 2017). When the goal is to reveal the effects of species mixing and structural diversity on the resistance and resilience of forest ecosystems, prior work is needed to quantify the climate sensitivity of productivity rates within a sound inferential framework.

In the present study, climate sensitivity was analyzed for various tree species and focus was placed on possible mixing effects. A short overview is given below of existing findings on the variation in climate sensitivity among different tree species and how sensitivity is influenced by site factors, species diversity, and other relevant structural measures.

According to tree-ring analyses, sessile oak [Quercus petraea (Matt.) Liebl.] has a relatively low climate sensitivity (Lebourgeois et al. 2004; Härdtle et al. 2013). Repeated measures of sample plot data from a monitoring network in France revealed that sessile oak trees from drier sites were less sensitive to the 1976 drought and recovered more rapidly (Trouvé et al. 2017). However, suppressed trees in higher density stands had slower recovery rates than dominant trees did.

Similar findings were made for Scots pine (Pinus sylvestris L.), in that the climate sensitivity of pine trees was generally reduced in sites with lower soil water holding capacity (Oberhuber et al. 1998; Linderholm 2001; Rigling et al. 2001; Morán-López et al. 2014). In comparison with Scots pine, sessile oak was more sensitive to soil water deficits in spring, whereas Scots pine had a higher sensitivity to summer droughts (Merlin et al. 2015; Toïgo et al. 2015). Analyses of ${ }^{13} \mathrm{C}$ carbon isotope concentrations in tree rings showed that the severe 2003 summer drought had a stronger impact on pine than on oak in the Orléans forest in France (Bonal et al. 2017). In the same geographical region, the wood density of pine significantly decreased during the drought, but the density of oak slightly increased (Toïgo et al. 2015).
Scots pine's climate-related response was primarily influenced by tree-level attributes (Martínez-Vilalta et al. 2012), such as age or size. Younger pine trees showed a higher climate sensitivity (Linderholm and Linderholm 2004), although the opposite was found by Merlin et al. (2015), who showed that smaller pines exhibited a stronger resistance and higher resilience than larger pine trees did. In contrast, the climate sensitivity of oak was not demonstrably affected by tree size (Merlin et al. 2015). The mixing of Scots pine and sessile oak seemed to have no significance in terms of the magnitude of their climate sensitivity (Merlin et al. 2015; Toïgo et al. 2015; Bonal et al. 2017).

In comparison with sessile oak, European beech (Fagus sylvatica $\mathrm{L}$.) proved to be more sensitive to drought and showed slower post-drought recovery rates (Cavin et al. 2013). In coexistence scenarios, the climate sensitivity of beech was reduced (Pretzsch et al. 2013), but sessile oak benefited from a release effect (Cavin et al. 2013) due to reduced competition from beech.

European beech trees had a higher climate sensitivity, i.e., a lower resistance, within the core region of its distribution area (Cavin and Jump 2017). Consequently, beech showed a lower sensitivity at the edges of its distribution range; see Fotelli et al. (2009) for results from northwestern Greece, Rose et al. (2009) for results from Poland, and Weber et al. (2013) for results from the Swiss Inner Alps. However, environmental changes in the past might have led to the increased climate sensitivity of beech, especially in sites with higher elevation (Dittmar et al. 2003).

Regarding the effects of species mixing, beech was found to have a lower climate sensitivity when surrounded by allo-specific trees, i.e., trees of different species (Metz et al. 2016). This might have been caused by enhanced water use efficiency, which was pronounced when beech was mixed with Scots pine (Conte et al. 2018). However, contrasting results were also found, as beech produced higher stem increments in a single-species context during the 2015 drought (Rötzer et al. 2017) or showed a higher resistance in mixed stands in drier sites (Schäfer et al. 2017).

When compared with beech, Norway spruce [Picea abies (L.) H. Karst.] showed a higher sensitivity (lower resistance) to the 2015 drought (Pretzsch et al. 2018), and the same was true for drier sites in general (Schäfer et al. 2017). The mixture with Norway spruce increased the resistance of European beech in moist sites, whereas in drier sites pure stands showed a higher resistance (Schäfer et al. 2017). Norway spruce suffered from the mixture with beech, especially during dry and hot years (Vospernik and Nothdurft 2018). However, the opposite findings were also found, in that mixture with beech did not lead to an increased drought susceptibility in spruce (Goisser et al. 2016).

The climate sensitivity of spruce and beech was strongly dependent on tree size. Dominant Norway spruce trees 
suffered more from drought than did intermediate or smaller trees (Pretzsch et al. 2018; Vospernik and Nothdurft 2018), but the opposite was observed for European beech, of which larger trees were less affected by soil water deficits. However, significant shifts with respect to these patterns could not be detected in response to species mixing (Pretzsch et al. 2018).

In mesic sites in the Inner Alpine region, Norway spruce and European larch (Larix decidua Mill.) were more sensitive to soil water deficits than other conifers were, including Scots pine, black pine (Pinus nigra J.F. Arnold), and Douglas fir [Pseudotsuga menziesii (Mirb.) Franco] (Lévesque et al. 2014). Norway spruce had higher climate sensitivity than did silver fir (Abies alba Mill.) or Douglas fir in southwest Germany (Van der Maaten-Theunissen et al. 2013; Vitali et al. 2017). In mixed stands, both spruce and fir species showed an increased sensitivity compared with singlespecies scenarios (Dănescu et al. 2018).

A major goal of the present study was to quantify the climate sensitivity of relevant tree species growing in a case study region in Lower Austria. In particular, trees' response to possible fluctuations in and extremes of climate observed in the past was evaluated. The analysis was based on treering time series from stem cores and a novel methodological framework that has been presented in Nothdurft and Vospernik (2018). The method applied was based on generalized additive models with penalized regression splines for a distributed lag model, which takes into account smooth, nonlinear, and time-lagged effects of a series of monthly climate values as well as their interactions. We demonstrated how climate sensitivity of forest trees can be determined using predictions of conditional expectations within a sound inferential framework.

From an ecological perspective and considering the results of previous studies, it was hypothesized that the tree species examined in the present study can be grouped with respect to their climate sensitivity (resistance) as follows: Norway spruce and European larch should possess high climate sensitivity (low resistance), European beech is intermediate, and sessile oak and Scots pine are assumed to have low climate sensitivity (high resistance). As broad evidence for the possible effects of species mixing on the climate sensitivity is currently lacking, a general null hypothesis was postulated, which states that species mixing does not influence the climate sensitivity of the examined tree species.

\section{Materials and methods}

\section{Survey plots}

Sample plots were established as triplets, each of which comprised three survey plots. Among these, a single plot was arranged in a mixed stand composed of two tree species, and the other two plots were placed in pure stands of the respective tree species. The triplets were installed for three tree species combinations: (1) sessile oak-Scots pine (oak-pine), (2) European beech-Norway spruce (beech-spruce), and (3) European beech-European larch (beech-larch). Each of these species combinations was generally represented by a single triplet, except for oak-pine, for which two triplets were established. One oak triplet will be treated as a non-managed plot and the other as a managed plot in future periods. All triplets were located in the Austrian federal state of Lower Austria, with the oak-pine triplets located near the village Maissau $\left(48^{\circ} 34^{\prime} 01^{\prime \prime} \mathrm{N}, 15^{\circ} 48^{\prime} 45^{\prime \prime} \mathrm{E}\right)$ and the other triplets near Kreisbach $\left(48^{\circ} 05^{\prime} 39^{\prime \prime} \mathrm{N}, 17^{\circ} 39^{\prime} 48^{\prime \prime} \mathrm{E}\right)$. The non-managed variant of the oak-pine triplets was named Maissau-Kuhberg, and the managed variant Maissau-Wilhelmsdorf.

According to records on past management activities, oak trees were thinned from below in the Maissau-Kuhberg plots during the winter of 1988/1989. In the Maissau-Wilhelmsdorf plots, only dying trees, mainly pines, were felled in 1993, 1995, and 1996 because of sanitary considerations. Relevant thinning activities were only applied during a short period from 1978 to 1987 in the beech-spruce and beech-larch stands in Kreisbach. In summary, the triplet plots can be regarded as having been nearly non-managed in the past.

Soils were characterized by loose sand and loam over weathered granite in the Maissau site and as sand-loam flysch in the Kreisbach site. The corresponding soil types were classified as dystric Cambisols in Maissau and dystric Planosols in Kreisbach. Soil moisture was moderately dry in Maissau and dry-wet in Kreisbach. The terrain in Maissau was flat, and the slope was $20^{\circ}-30^{\circ}$ in Kreisbach. The site index, in terms of the average height of dominant trees at a stand age of 100 years, was $23 \mathrm{~m}$ for oak and $25.8 \mathrm{~m}$ for pine in Maissau and $35.4 \mathrm{~m}$ for beech, $35.7 \mathrm{~m}$ for larch, and $36 \mathrm{~m}$ for spruce in Kreisbach.

The sample plots had an average area of 0.27 ha [minimum (min.), 0.12 ha; maximum (max.), 0.61 ha; standard deviation (SD), $0.15 \mathrm{ha}$. If trees had a diameter at breast height (dbh) of greater than or equal to $7 \mathrm{~cm}$, the basal area on the plots was on average $42.6 \mathrm{~m}^{2}$ (min., $26.4 \mathrm{~m}^{2}$; max., $56.9 \mathrm{~m}^{2} ; \mathrm{SD}, 10.7 \mathrm{~m}^{2}$ ), and the average stem density was 642 stems per ha (min., 281; max., 1217; SD, 264) (see Table 1).

\section{Climate data}

The climate data were from the HISTALP dataset (Böhm et al. 2009). For each triplet location, monthly averages of atmospheric temperature and monthly totals of precipitation were derived via spatiotemporal predictions with generalized additive model approaches; see Nothdurft and Vospernik 
Table 1 Summary characteristics of sample plots at the Maissau and Kreisbach study sites

\begin{tabular}{|c|c|c|c|c|c|c|c|c|c|c|c|c|}
\hline \multirow[t]{2}{*}{ Site } & \multirow[t]{2}{*}{ Plot } & \multirow[t]{2}{*}{ Area (ha) } & \multirow{2}{*}{$\begin{array}{l}\text { Basal area } \\
\left(\mathrm{m}^{2} / \mathrm{ha}\right)\end{array}$} & \multirow{2}{*}{$\begin{array}{l}\text { Tree den- } \\
\text { sity (N/ha) }\end{array}$} & \multicolumn{4}{|c|}{$\operatorname{Dbh}(\mathrm{cm})$} & \multicolumn{4}{|c|}{ Height (m) } \\
\hline & & & & & Mean & Min. & Max. & SD & Mean & Min. & Max. & SD \\
\hline Maissau-K & Pure-oak & 0.19 & 27.6 & 386 & 27.1 & 7.4 & 48.9 & 13.2 & 17.2 & 4.4 & 26.6 & 6.7 \\
\hline Maissau-K & Pure-pine & 0.12 & 41.8 & 1217 & 20.2 & 8.3 & 34.5 & 5.3 & 19.0 & 6.9 & 24.7 & 3.2 \\
\hline Maissau-K & Mixed-oak-pine & 0.17 & 33.3 & 652 & 24.4 & 7.8 & 51.4 & 7.3 & 20.0 & 6.1 & 25.1 & 3.4 \\
\hline Maissau-W & Pure-oak & 0.28 & 26.4 & 281 & 33.6 & 11.3 & 51.6 & 8.3 & 19.0 & 8.3 & 25.4 & 3.0 \\
\hline Maissau-W & Pure-pine & 0.18 & 41.5 & 760 & 25.9 & 7.0 & 42.3 & 4.9 & 20.2 & 2.0 & 25.9 & 3.1 \\
\hline Maissau-W & Mixed-oak-pine & 0.35 & 35.0 & 516 & 27.9 & 7.0 & 61.4 & 9.3 & 19.3 & 2.0 & 26.7 & 4.4 \\
\hline Kreisbach & Pure-beech & 0.16 & 42.4 & 666 & 27.4 & 8.0 & 43.8 & 7.8 & 29.0 & 10.7 & 35.2 & 5.1 \\
\hline Kreisbach & Pure-spruce & 0.19 & 56.9 & 463 & 38.6 & 13.4 & 62.3 & 8.7 & 30.2 & 15.7 & 34.3 & 3.1 \\
\hline Kreisbach & Mixed-beech-spruce & 0.61 & 43.6 & 488 & 32.0 & 9.1 & 68.0 & 10.7 & 28.7 & 4.4 & 38.5 & 5.4 \\
\hline Kreisbach & Pure-beech & 0.16 & 55.6 & 740 & 29.6 & 14.1 & 65.9 & 9.0 & 31.5 & 19.5 & 37.3 & 4.4 \\
\hline Kreisbach & Pure-larch & 0.32 & 55.5 & 1005 & 24.4 & 7.1 & 55.9 & 10.3 & 24.0 & 7.0 & 34.4 & 6.5 \\
\hline Kreisbach & Mixed-beech-larch & 0.49 & 51.6 & 528 & 33.6 & 7.6 & 63.3 & 10.6 & 33.1 & 6.9 & 41.6 & 5.7 \\
\hline
\end{tabular}

(2018) for further details. The summary characteristics of the interpolated climate data are presented for a constant period from 1950 to 2017 (Figs. 1, 2), covering 95\% of the Kreisbach data and $79 \%$ of the Maissau data. For this period, the long-term average of the mean annual temperature was almost equal in Kreisbach $\left(7.41^{\circ} \mathrm{C}\right)$ and Maissau $\left(7.37^{\circ} \mathrm{C}\right)$. The mean annual temperature ranged from 5.9 to $9.5^{\circ} \mathrm{C}$ in Kreisbach and from 5.6 to $9.3{ }^{\circ} \mathrm{C}$ in Maissau. The warmest month was July, with a long-term average temperature of $17.0^{\circ} \mathrm{C}$ at both sites. The monthly mean temperatures in July ranged from 14.4 to $21.0^{\circ} \mathrm{C}$ in Kreisbach and between 13.8 and $21.2^{\circ} \mathrm{C}$ in Maissau. January had the coldest longterm average temperature with $-2.5{ }^{\circ} \mathrm{C}$ at both sites. The monthly mean temperatures in January ranged between -7.8 and $2.5^{\circ} \mathrm{C}$ in Kreisbach and between -7.9 and $2.7^{\circ} \mathrm{C}$ in Maissau. The summary characteristics of monthly temperature were relatively similar in Kreisbach and Maissau, but the two sites showed larger differences with respect to monthly rainfall. The long-term average annual precipitation was $811 \mathrm{~mm}$ in Kreisbach and $551 \mathrm{~mm}$ in Maissau. The total annual precipitation ranged between $557 \mathrm{~mm}$ and $1170 \mathrm{~mm}$ in Kreisbach and $356 \mathrm{~mm}$ and $778 \mathrm{~mm}$ in Maissau. In Kreisbach, the highest monthly precipitation occurred in July with an average of $107 \mathrm{~mm}$ (min., $28 \mathrm{~mm}$; max., $254 \mathrm{~mm}$ ), and in Maissau the highest precipitation occurred in June with an average of $76 \mathrm{~mm}$ (min., $22 \mathrm{~mm}$; max., $164 \mathrm{~mm}$ ).

\section{Tree-ring data}

According to prior regulations for field work, we collected tree-ring cores from 30 trees per species and sample plot, of which 20 trees had a dominant social status and 10 trees a subdominant status. However, a few sample cores were irreparably damaged during transport or later preparation.
Fig. 1 Distribution of average monthly temperature at the Kreisbach and Maissau study sites during 1950-2017. Black line, mean; light-gray areas, range between minimum and maximum; medium-gray areas, range between 5th and 95th percentiles; dark-gray areas, interquartile range

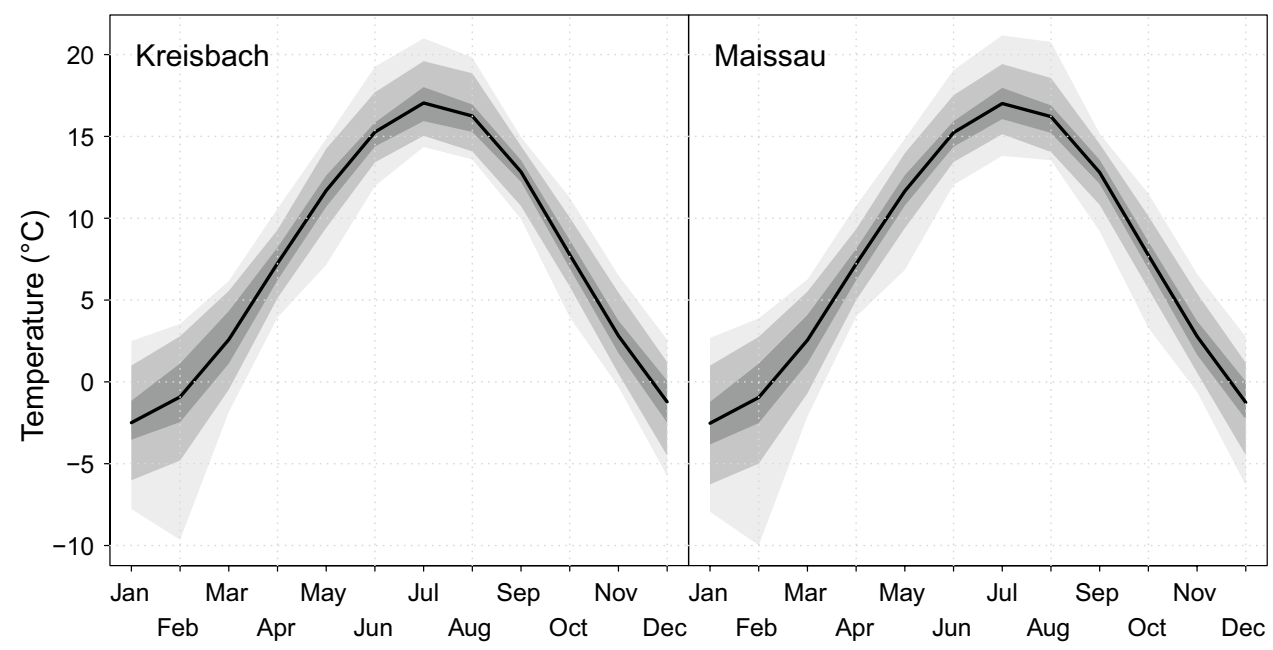


Fig. 2 Distribution of total monthly precipitation at the Kreisbach and Maissau study sites during 1950-2017. Black line, mean; light-gray areas, range between minimum and maximum; medium-gray areas, range between 5 th and 95 th percentiles; dark-gray areas, interquartile range

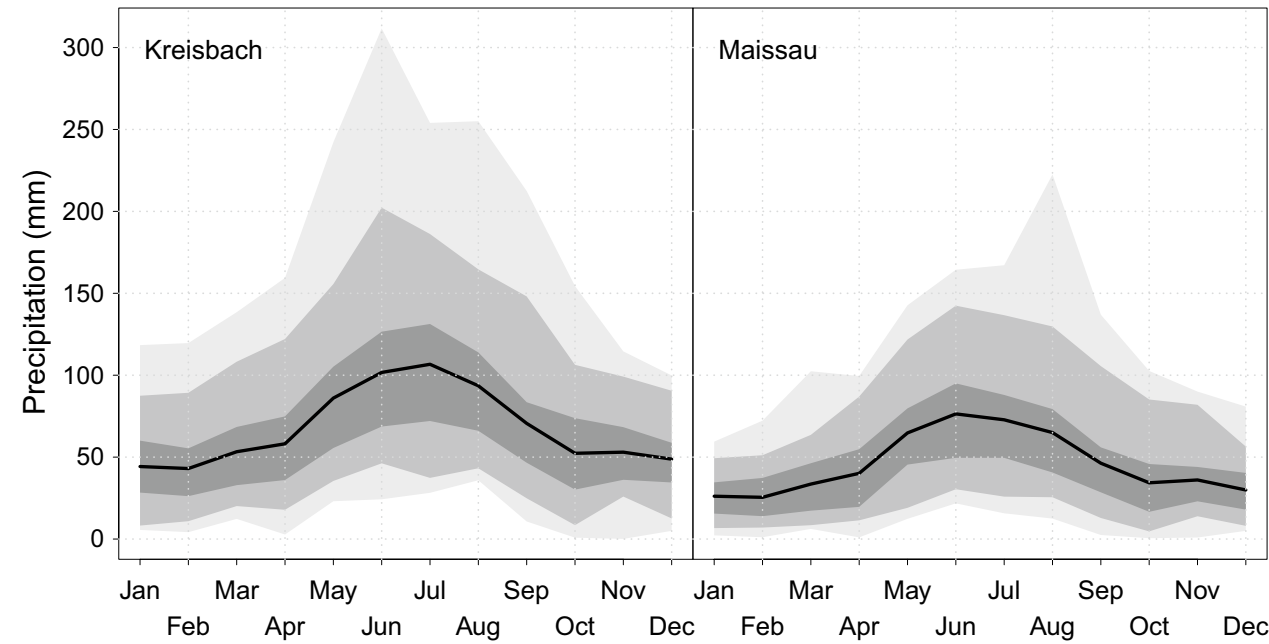

Thus, usable tree-ring cores were available for a minimum of 28 oak trees from the oak-pine mixed stand in Maissau-Wilhelmsdorf and 28 spruce trees from the beech-spruce mixed stand (Table 2). A few reserve trees were additionally probed, and tree-ring cores were consequently available for a maximum of 32 beech trees in the beech-spruce and beech-larch mixed stands.

The sampled trees from the beech-spruce and beech-larch triplets had relatively similar ages. For the former, the average age per tree species ranged from 61 years for the pure spruce variant to 72 years for the pure beech variant (see Table 2). The sampled trees from the pure larch plot had an average age of 67 years, and the beech trees from the beech-larch mixed stand had an average age of
79 years. In contrast, the sample trees from the two oak-pine triplets showed a larger variation with respect to their age, and the sampled trees from the Maissau-Kuhberg triplet had younger ages than those from the Maissau-Wilhelmsdorf triplet. In Maissau-Kuhberg, the pine trees on the mixed stand had the youngest mean age of 49 years, whereas the oak trees in the pure stand had the oldest age of 84 years. In Maissau-Wilhelmsdorf, the oak trees on the mixed stand had the youngest age of 87 years, and the pine trees on the pure plot had the oldest age of 122 years.

Two wood cores were extracted per sample tree at breast height (1.3 $\mathrm{m}$ above the ground) using an increment borer. The two cores were drilled in a radial direction toward the pith, and the cores were aligned orthogonally to each other, one from

Table 2 Summary characteristics of sample tree species

\begin{tabular}{|c|c|c|c|c|c|c|c|c|c|c|c|c|c|c|c|}
\hline \multirow[t]{2}{*}{ Site } & \multirow[t]{2}{*}{ Species } & \multirow[t]{2}{*}{ Mixture } & \multirow[t]{2}{*}{ Trees } & \multicolumn{4}{|c|}{ Age (years) } & \multicolumn{4}{|c|}{ Dbh $(\mathrm{cm})$} & \multicolumn{4}{|c|}{ Height (m) } \\
\hline & & & & Mean & Min. & Max. & SD & Mean & Min. & Max. & SD & Mean & Min. & Max. & SD \\
\hline Maissau-K & Oak & Pure & 30 & 84 & 34 & 95 & 12 & 29.5 & 9.3 & 40.3 & 9.2 & 18.9 & 4.4 & 26.6 & 5.2 \\
\hline Maissau-K & Oak & Oak-pine & 29 & 56 & 41 & 81 & 13 & 22.6 & 9.4 & 38.4 & 8.9 & 19.2 & 8.4 & 25.1 & 3.9 \\
\hline Maissau-K & Pine & Pure & 30 & 66 & 56 & 84 & 7 & 22.1 & 12.9 & 29.5 & 4.1 & 20.4 & 14.5 & 24.7 & 1.9 \\
\hline Maissau-K & Pine & Oak-pine & 31 & 49 & 34 & 54 & 4 & 21.4 & 10.9 & 29.6 & 3.1 & 19.8 & 13.6 & 23.2 & 2.0 \\
\hline Maissau-W & Oak & Pure & 30 & 97 & 77 & 108 & 10 & 35.1 & 20.6 & 49.1 & 7.9 & 19.5 & 14.8 & 23.9 & 2.0 \\
\hline Maissau-W & Oak & Oak-pine & 28 & 87 & 67 & 111 & 15 & 28.3 & 9.4 & 48.0 & 10.3 & 18.7 & 5.8 & 24.9 & 4.8 \\
\hline Maissau-W & Pine & Pure & 31 & 122 & 79 & 148 & 12 & 27.2 & 18.8 & 36.2 & 4.3 & 20.3 & 13.2 & 23.9 & 2.4 \\
\hline Maissau-W & Pine & Oak-pine & 30 & 103 & 78 & 130 & 15 & 28.1 & 8.4 & 47.1 & 9.7 & 19.1 & 9.6 & 26.1 & 4.6 \\
\hline Kreisbach & Beech & Pure & 30 & 72 & 46 & 82 & 6 & 32.1 & 18.9 & 43.6 & 6.0 & 31.8 & 26.4 & 35.0 & 1.8 \\
\hline Kreisbach & Beech & Beech-spruce & 32 & 68 & 50 & 73 & 4 & 35.9 & 15.4 & 54.4 & 9.1 & 29.8 & 20.9 & 33.8 & 3.1 \\
\hline Kreisbach & Spruce & Pure & 30 & 61 & 48 & 71 & 5 & 42.9 & 28.4 & 62.3 & 8.3 & 31.7 & 27.6 & 34.3 & 1.9 \\
\hline Kreisbach & Spruce & Beech-spruce & 28 & 64 & 53 & 70 & 5 & 35.5 & 21.8 & 54.2 & 7.4 & 30.6 & 25.2 & 35.3 & 2.2 \\
\hline Kreisbach & Beech & Pure & 30 & 71 & 41 & 77 & 7 & 35.8 & 15.2 & 46.4 & 8.2 & 33.3 & 19.5 & 37.3 & 4.0 \\
\hline Kreisbach & Beech & Beech-larch & 32 & 79 & 71 & 89 & 4 & 39.6 & 16.9 & 63.3 & 10.3 & 34.7 & 22.4 & 39.3 & 3.9 \\
\hline Kreisbach & Larch & Pure & 30 & 67 & 61 & 70 & 2 & 33.6 & 25.8 & 40.7 & 3.6 & 29.4 & 24.8 & 33.0 & 2.0 \\
\hline Kreisbach & Larch & Beech-larch & 29 & 78 & 68 & 86 & 4 & 41.7 & 29.4 & 54.0 & 7.1 & 36.3 & 29.8 & 41.6 & 3.2 \\
\hline
\end{tabular}


the north and the other from the east. The sample cores were sanded prior to the tree-ring measurements. Tree-ring widths were measured with $0.01 \mathrm{~mm}$ precision using TSAP-Win software (RINNTECH, Heidelberg, Germany) and a Johann digital positiometer (BIRITS GmbH, Austria) mounted on a LINTAB station (RINNTECH). Cross-dating was performed visually and guided by pointer years. The cross-dated ring width measurements from the two cores were averaged for each tree for the respective calendar years.

\section{Distributed lag models}

The annual radial increment was modeled using an approach recently presented by Nothdurft and Vospernik (2018). The approach was based on a generalized additive model with penalized regression splines and a distributed lag model accounting for time-lagged effects of climate variables and their interactions. Model fitting was performed with the $\mathrm{mgCV}$ package (Wood 2003, 2004, 2011) in R (Core Team 2018). Unlike in the study of Nothdurft and Vospernik (2018), where Gaussian assumptions were met, the present tree-ring width data were right-skewed and had heterogeneous variance. After systematic and comprehensive tests of Gaussian, gamma, and Tweedie (Tweedie 1984) distributional assumptions for all the species and mixture scenarios as well as for a broad sequence of maximum lag ranges, the Tweedie distribution achieved the lowest Akaike information criterion (AIC) (Akaike 1973) values and was chosen for our final model fits.

The Tweedie distribution belongs to the exponential family, and the variance $\operatorname{Var}(\mu)=\phi \mu^{p}$ is given by the mean $\mu=\mathbb{E}(y)$ of the response $y$ to the power $p$. In mgcv, $p$ can be either fixed heuristically or estimated via maximum likelihood. If $p$ is estimated, it is restricted to lie within the interval $p \in(1,2)$. In this case, i.e., $(1<p<2)$, a Tweedie random variable follows a compound Poisson-gamma mixture distribution. Therefore, the Tweedie random variable can be expressed by the sum $\sum_{i=1}^{N} Y_{i}$ of $N \sim \operatorname{Po}(\lambda)$ Poisson-distributed gamma random variables $Y_{i}=\Gamma(\alpha, \theta)$, with the rate parameter of the Poisson distribution being $\lambda=\mu^{2-p} /\{\phi(2-p)\}$ and with $\alpha=(2-p)(p-1)$ and $\theta=\phi(p-1) \mu^{p-1}$ as the shape and scale parameter of the gamma distribution, respectively (Wood 2017).

Given these restrictions, the Tweedie random variable was nonnegative and continuous, and it had a positive mass at zero. Use of the mgcv-default in the form of the following logarithmic link was successful:

$$
\begin{aligned}
& \log \left[\mathbb{E}\left(y_{i}\right)\right]=\eta_{i} \\
& y_{i} \sim \text { Tweedie }
\end{aligned}
$$

with the Tweedie distributed response vector of year-ring width measurements $y_{i}$ for tree $i$ and the associated linear predictor $\eta_{i}$.
A major benefit of the proposed generalized additive model framework is that both the "detrending" of the individual tree-ring width series and the regression modeling were performed simultaneously in a single model step.

With these prerequisites, the linear predictor becomes:

$$
\begin{aligned}
\eta_{i}=f_{i}\left(\text { Age }_{i}\right)+g\left(\text { Age }_{i}\right) \\
\quad+\sum_{k=1}^{l} \gamma\left(\text { Temp }_{i k}, \operatorname{lag}_{i k}\right)+\sum_{k=1}^{l} \delta\left(\operatorname{Prec}_{i k}, \operatorname{lag}_{i k}\right) \\
\quad+\sum_{k=1}^{l} \kappa\left(\operatorname{Temp}_{i k}, \operatorname{Prec}_{i k}, \operatorname{lag}_{i k}\right) .
\end{aligned}
$$

where $f_{i}\left(\mathrm{Age}_{i}\right)$ represents individual detrending by capturing the medium-term oscillation of each tree-ring width series with separate functions $f_{i}$. As formerly applied by Nothdurft and Vospernik (2018), the functions $f_{i}$ were constructed by flexible Duchon splines (Duchon 1977) with first-order derivative penalties. The second term $g\left(\right.$ Age $\left._{i}\right)$ models a population-average long-term age effect with thin plate regression splines, possibly reflecting the influence of senescence on tree-ring width. The three sum terms in Eq. 2 represent the distributed lag model and describe the effect of climate in terms of monthly average temperatures, monthly total precipitation, and their interactions for a retrospective period. The first sum term $\sum_{k=1}^{l} \gamma\left(\mathrm{Temp}_{i k}, \operatorname{lag}_{i k}\right)$ models the effect of average monthly temperatures, $\mathrm{Temp}_{i k}$ is the average monthly temperature in $\operatorname{lag}_{i k}=(k-1)$ months prior to the latest considered month, and $l$ is the maximum number of lags. The function $\gamma$ is a two-dimensional tensor product interaction smooth constructed by cubic regression spline (CRS) bases. Thus, $\gamma$ builds a surface that behaves smoothly in the directions of both axes, along the temperature and across the lags. The second sum term $\sum_{k=1}^{l} \delta\left(\operatorname{Prec}_{i k}, \operatorname{lag}_{i k}\right)$ analogously models the time-lagged effects of total monthly precipitation across the lags, similarly using a two-dimensional tensor product interaction smooth with CRS bases in $\delta$. Whereas the first two sum terms represent main climate effects, the third sum term $\sum_{k=1}^{l} \kappa\left(\operatorname{Temp}_{i k}, \operatorname{Prec}_{i k}, \operatorname{lag}_{i k}\right)$ reflects the interaction effects between temperature and precipitation. This term was modeled as a three-dimensional tensor product interaction smooth with CRS. CRSs, which are provided as default spline basic functions by $\mathrm{mgCV}$ for tensor product smooths and tensor product interaction smooths, were used for climate-related terms, because they are less computationally expensive than thin plate regression splines are.

Although the linear predictor in Eq. 2 is relatively complex, it can be intuitively interpreted from two perspectives. First, the model can be characterized as a functional random effects model with respect to the collection of 
Duchon spline smoothers, each of which has its own penalties. Second, it can be termed as a functional ANOVA model with respect to the climate effects decomposed into smooth main effects and interactions.

\section{Raster search for optimal range of distributed lag model}

Trials have failed to build a single regression model for the complete dataset covering all tree species with their corresponding mixture scenarios. This failure is due to the manifold and complex nonlinear structures of the time-lagged climate effects among the different species and mixture scenarios, which cannot be modeled by simple offset parameters and slope adjustments for dummy-coded species/mixture categories. In addition, the lag structure, i.e., the maximum number of lags, may differ among the species and mixture scenarios, which hinders the application of a single varyingcoefficient model with separate smooths for each species and mixture category. Hence, different models were fitted for each tree species and mixture scenario combination using the linear predictor in Eq. 2 and the Tweedie distributional assumptions.

Consequently, the distributed lag models were specified separately for each tree species and mixture scenario. However, the most recently considered month, i.e., the minimum lag, was constantly set as September of the current year for all species and mixture scenario combinations. The temperature and precipitation in the latest considered month, $\mathrm{Temp}_{i 1}$ and $\operatorname{Prec}_{i 1}$ with $l=1$ and $\operatorname{lag}_{i 1}=0$, were set as the average temperature and total precipitation in September of the current year.

In contrast to the uniform end point of the different lag series, the maximum number of lags $l$ was separately determined for each tree species and mixture scenario using a raster search. In doing so, separate full models were fitted for different lengths $(l)$ of the lag series. For each of the available species/mixture combinations, $l$ was chosen from a sequence of integers with a minimum value of 9 and a maximum of 65 . That is, in this optimization, climate variables should be considered as early as May 5 years prior to the current year in which the observed ring width was produced.

The performance of the different candidates for an optimal distributed lag model was assessed by means of the AIC. Restricted models were also fitted, in which the sum terms of the tensor product interactions were set to zero, meaning that climate effects were not considered. The proportion of the deviance explained by all model candidates was evaluated by comparing it to the corresponding restricted models. This relative measure was analogous to the partial $R^{2}$ from linear model theory and indicated the extent to which the smooth terms for the climate variables were able to explain the "variance" of the tree-ring width (response) data.

\section{Evaluation of climate effects}

To evaluate the possible effects of monthly climate variables on the trees' response (tree-ring width), the climate effects of the distributed lag model were evaluated using the linear predictor by fixing the lagged monthly temperature and precipitation to their respective median values, except for a single lagged variable. For this variable, an equally spaced sequence of new data was generated within the 2.5th-97.5th percentile range of the variable. Tree age was fixed at 40 years, roughly corresponding to the overall median of 41 years, to guarantee a constant reference age.

\section{Predictions with simulated climate sequences}

To quantify the climate sensitivity and the resistance of each tree species under both mixture scenarios, we assessed how climate, in conjunction with the mixture scenario, could modify the annual radial increment of the examined tree species. For this purpose, the distributed lag models were run with simulated sequences of past observed climate data. To achieve a fair comparison among the simulations for the different species and mixture scenarios, a common reference period was defined from which the climate data were sampled. Hence, predictions of conditional expectations were calculated with climate data from at least a common time period for which tree-ring width observations were available for each species and mixture scenario. This particular time period was from 1949 to 2017. For each plot location and year, the temporal sequence of the observed monthly climate variables was fixed during the simulation.

In each run of the simulation, a random sample of size $n$ was chosen from the 69 years in the sequence of 1949-2017. The sample size $n$ corresponded to the number of years covered by a specific distributed lag model. As the distributed lag models for the different tree species and mixture scenarios varied in their optimal number of lags $l$, the number of associated years $n$ likewise differed among the species and mixture scenarios. In practice, climate data from a minimum of 2 years were required for the oak model predictions, and for those of the pine model for pure-stand scenarios. Data from a maximum of 6 years were required for the regression models of both pure beech stands.

Sampling was conducted with replacement. Thus, a specific annual climate period was selected by chance multiple times. As the order of the sampled years had to be considered, e.g., $(1980,1981)$ differed from $(1981,1980)$, the number of possible settings in each simulation run was given by the number of possible permutations for $n$ out of 69 elements. Consequently, a minimum number of $69^{2}=4761$ permutations was possible for the simulations of the annual climate sequences with the oak and pure pine models, and a maximum number of $69^{6}=1.079 \mathrm{e}+11$ permutations was 
possible for the pure beech models. Since a complete evaluation of the possible permutations was numerically unfeasible for the models with larger values of $l$, and to save computation time, a constant number of 5000 simulations was chosen for all models. Finally, such as for the evaluation of marginal climate effects, tree age was fixed at a constant age of 40 years for all tree species and both mixture scenarios.

\section{Measures of climate sensitivity and resistance}

The main purpose of the simulation was to provide credible information on the climate sensitivity of annual tree growth rates and on the possible severity of relative growth depressions under unfavorable climate conditions. In this study, climate sensitivity was evaluated in terms of the $95 \%$ prediction interval, which was calculated as the difference between the 97.5 th and 2.5 th percentile of the 5000 predictions for the simulated climate sequences. "Sensitivity" has a different meaning in traditional dendrochronological studies, and "mean sensitivity" was introduced by Douglass (1936) and adapted by Fritts (1976) and Schweingruber (1983) to express the average relative change in tree-ring width between two consecutive years. However, it should be noted that "mean sensitivity" can reflect any changes due to a vast number of factors implied by the term "environmental conditions," and it has therefore not been named "mean climate sensitivity" in the literature. Thus, our definition of climate sensitivity does not conflict with the classical term "mean sensitivity."

The effect size regarding the possible climate-related growth depression was evaluated by the lower limit of the 95\% interval (i.e., the 0.025 quantile) of the posterior distribution of the simulations in this study. According to a general ecological definition given in Levin (2009), the term "resistance" means "the ability of an ecosystem to withstand disturbance without major change in structure and function." The lower limit of the simulated predictions was subsequently termed "resistance."

Differences in climate sensitivity and resistance among the examined tree species, induced by the mixture with other species, were expressed in terms of relative differences in the absolute measures (absolute climate sensitivity and resistance) and the differences in percentage points of relative measures (relative climate sensitivity and resistance). The latter were derived from divisions of the absolute measures by the respective averages per species and mixture scenario.

Hence, the relative difference (change) in the absolute climate sensitivity induced by species mixture was evaluated per species as the relative percentage difference between the absolute climate sensitivities (range of the 95\% prediction interval) of the pure- and mixed-stand scenarios. The difference in the relative percentage climate sensitivity was calculated in percentage point units, i.e., the relative percentage climate sensitivity of the purestand scenario was subtracted from that of the mixedstand scenario. This procedure was likewise applied to the resistance measures. Thus, the relative percentage differences in the absolute resistances (2.5th percentiles of the simulations) was evaluated per species as the relative percentage difference between the absolute resistances of the pure- and mixed-stand scenarios. The differences in the relative percentage resistances were calculated in percentage point units, i.e., the relative percentage resistance of the pure-stand scenario was subtracted from that of the mixed-stand scenario.

The rationale of using simulation-based inferences and assessing the possible effects of species mixture via summary statistics of the simulation results was based on fundamental statistical theory. It may be technically possible to use frequentist tests, e.g., in terms of parametric $t$ tests or ANOVA-based methods. However, in frequentist tests, $p$ values are determined by statistical power, which is strongly dependent on replications (i.e., number of simulations) and the effect size. With massive replications, the $t$ - or $F$-distributed test statistic becomes large. Thus, given a large number of replications, $p$ values become "minuscule," even for small differences (effect sizes) (White et al. 2014). Consequently, large sample sizes, as are usually applied in simulations, would produce significant results irrespective of the magnitude of the biological effect size. Even more significant results could be produced by increasing the number of simulations. Hence, significance is no longer determined by the power of the test but rather by the available computer power or the waiting time that the programmer is willing to spend on the simulations. This reduces the meaning of parametric test results, especially in terms of $p$ values, to absurdity.

If data are analyzed in ecological studies, biological significance is often confused with statistical significance (see examples in Johnson 1999). A crucial premise of a frequentist approach is that the null hypothesis is assumed to be valid. However, assuming a null hypothesis implies that inferences were drawn from populations with identical distributions. This is not reasonable in the present study. Because the models are known to have different parameters, it is known a priori that the null hypothesis is false. Thus, using a frequentist approach to test the null hypothesis, which is known a priori to be false, is pointless and may yield misleading results, especially when the task is to compare simulation outputs from models that have different parameters and/or functional terms.

White et al. (2014) argued that the question is not whether the outcomes from the different models will be different, but rather how large the differences will be. This could be credibly answered by comparing the summary statistics of the massive simulations and through simple graphical means, i.e., in terms of the figures in this manuscript, providing 
information on the modes and quantiles of the posterior distributions.

\section{Results}

\section{Raster search for optimal range of lags}

The AIC and deviance explained did not show continuous changes across the different maximum number of lags, and a global optimum and other local optima appeared. This behavior is plausible, because the different number of maximum lags comprised different sets of monthly climate variables. As temperature and precipitation in different seasons (times of the year) had varying impacts on tree growth, the AIC and deviance explained were expected to show abrupt changes if an extra sequence of climate variables that comprised monthly variables from a complete growing season or winter period was considered. It is therefore plausible that the curves of the diagnostic criteria showed signs of cyclic (seasonal) trends, which were especially pronounced for beech.

The optimal number of lags evaluated via the minimum AIC varied among the tree species and between the two mixture scenarios associated with each species (Fig. 3). In the pure stands, beech had the largest optimum number of 59 lags (months) in both stands (Table 3), which suggests that a retrospective series of monthly climate variables should be considered in the regression model that dated back to November 5 years prior to the growing season in which the observed tree-ring width was produced. In the pure larch stand, an optimum number of 46 lags was found, i.e., the influence of past climate conditions reached back to December 4 years before the recent growing season. Compared with the other tree species in pure stands, the optimum distributed lag models for pine and oak had a relatively short range of 19 and 18 lags, respectively.

In its optimum configuration, the distributed lag model for the tree-ring width series from the pure beech plot in the beech-spruce plot achieved the highest deviance explained of $37.86 \%$. However, the models for pure-stand scenarios with larch, oak, beech from the beech-larch triplet, and spruce showed only slightly smaller deviances explained, ranging from $36.90 \%$ for larch to $33.48 \%$ for spruce. In contrast, and among the models for pure-stand scenarios, the optimum distributed lag model for pure pine had the lowest deviance explained of $24.56 \%$. Only for pure spruce did the model with the lowest AIC not provide the highest deviance explained. A model with 37 lags had a deviance explained of $36.09 \%$, instead of $33.48 \%$ achieved with 39 lags under a minimum AIC. For the other tree species, the models with the lowest AIC coincidentally showed the highest deviance explained.
When applied to tree-ring width data from mixed-stand scenarios, the distributed lag models had a smaller optimum number of lags in most cases. However, for oak in the oak-pine scenario, the optimum number of 18 lags was exactly the same as that for the pure oak plots. In the same mixed-stand scenario, the minimum AIC model for pine had a slightly higher number of 24 lags, compared with the 19 lags of the pure pine stand model. For the other tree species in the mixed-stand scenarios, the temporal ranges of the distributed lag models were considerably lower than those of the pure-stand models. The model for beech-spruce plots had an optimal number of 30 lags and was shorter by two growing seasons than the model for the pure beech stand. The range of the distributed lag model for beech-larch plots was likewise shortened by 23 lags compared with the pure beech plot from the associated triplet. The optimum range of the distributed lag models for mixed-stand scenarios was reduced from 39 to 25 lags for spruce and from 46 to 27 lags for larch.

For each tree species, the deviance explained by the climate-sensitive part of the regression model changed through the mixing condition in relation to the pure-stand scenario. In fact, the changes had a remarkable pattern, because the optimum lag model showed an increased deviance explained through mixing for one tree species, whereas the deviance explained was lowered for the other tree species. In the oak-pine triplets, the deviance explained for the oak model was lowered by 6.9 percentage points in the mixed-stand scenario compared with that in the pure stand, whereas it was increased by 5.1 percentage points for pine. In the beech-spruce triplet, species mixing reduced the deviance explained by 5.2 percentage points for beech and resulted in an increase of 2.8 points for spruce. The opposite outcome was obtained in the beech-larch triplet, and mixing increased the deviance explained by 4.4 percentage points for beech, but lowered the deviance explained by 9.3 points for conifer tree species larch.

For the tree-ring width data from the mixed-stand scenarios, models with different lag ranges than the optimum models existed in two cases that showed slightly higher deviances explained. This scenario occurred for pine in the oak-pine plot and beech in the beech-spruce plot. If the distributed lag model for pine increased by a single monthly lag, the deviance explained was marginally enhanced by 0.01 percentage points. A model with 36 instead of the optimum 30 lags for beech in the beech-spruce plots achieved a slightly increased deviance explained by 0.31 percentage points.

In summary, the influence of past climate conditions on tree-ring width reached farther back in pure-stand than in mixed-stand scenarios, except for pine, for which the opposite was observed. Thus, the period with the most relevant climate information was generally shortened by mixing. In 
рәu!̣|dxә әэuе!ıәр uo!̣ıodoגd

아
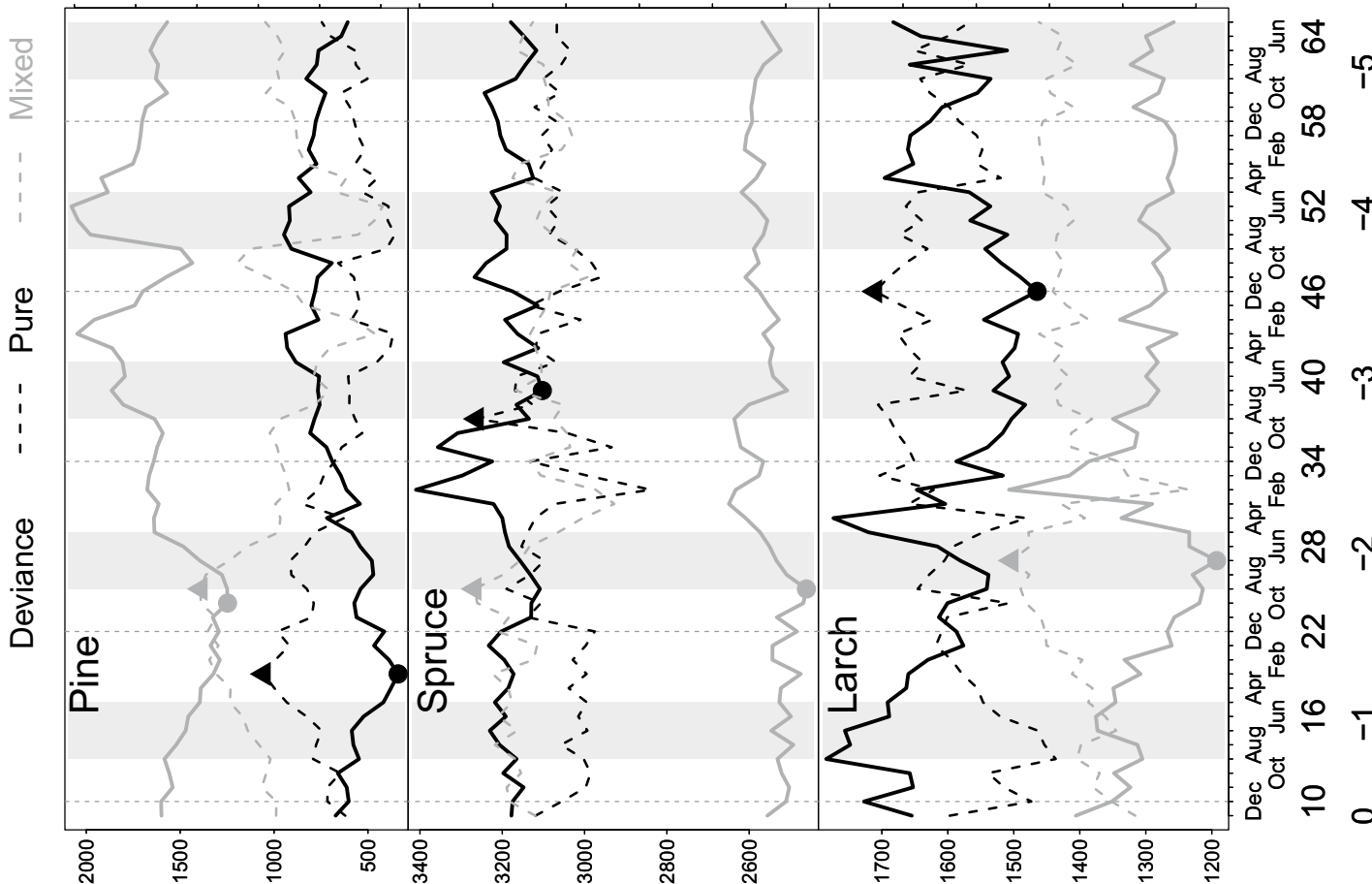

نூ讠

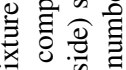

寻密焉

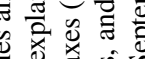

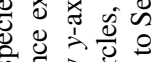

. ज्ञ

踣券

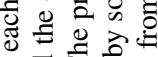

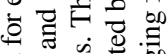

递焉焉

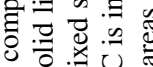

㐫各寻文

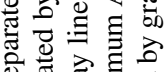

语的寻

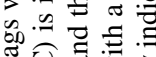

4 过

ธี

离氙芯

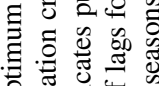

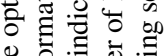

过导志

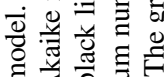

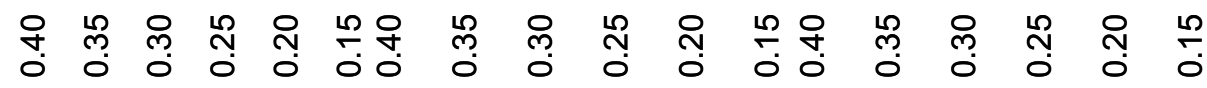

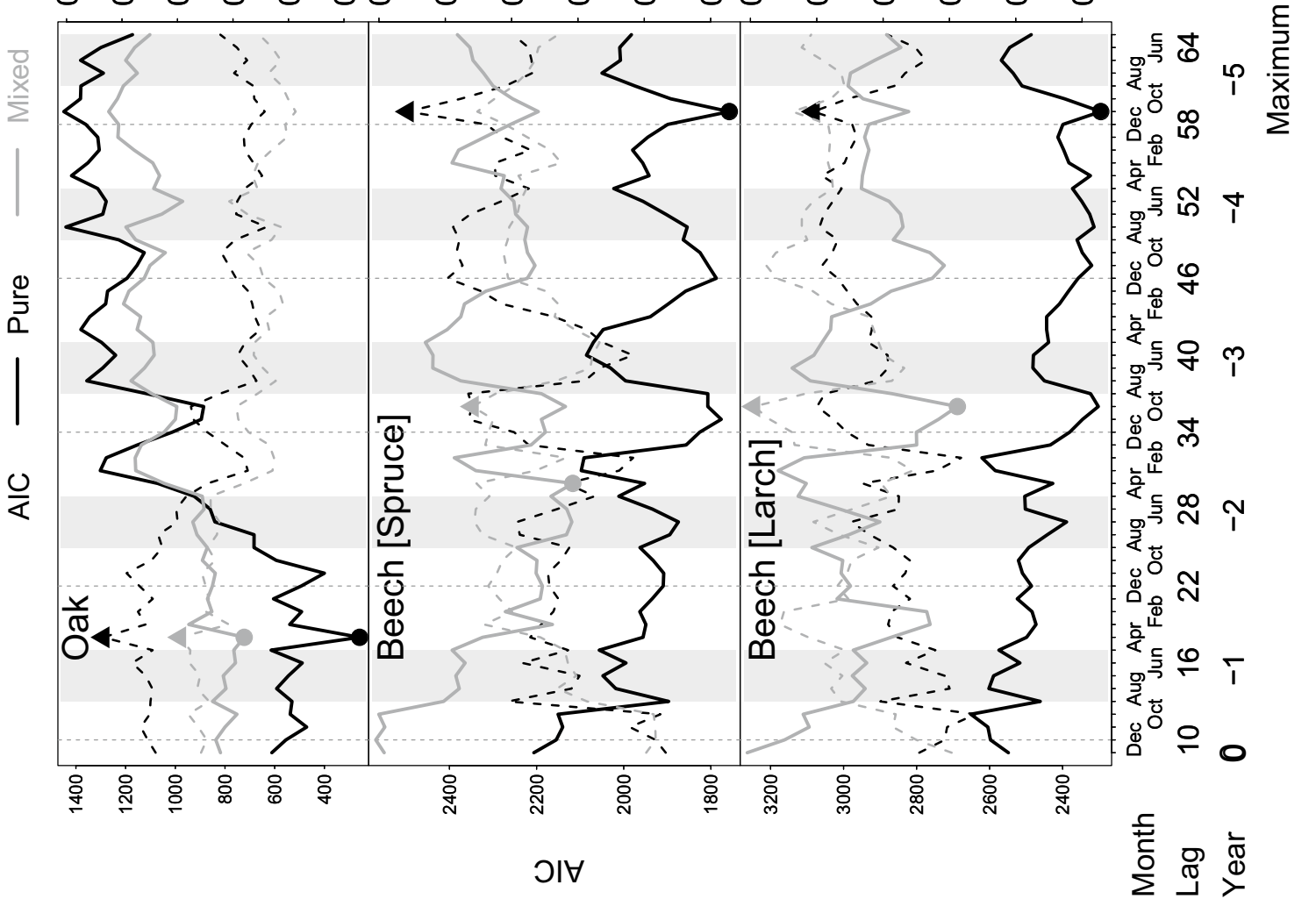

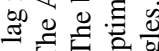

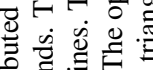

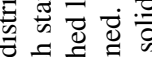

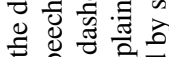

पेते

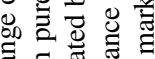

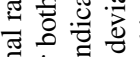

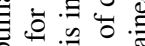

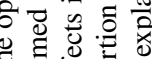

흉 융

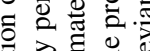

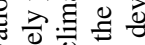

흉 클 웜

Ð

क जे

동 ڤ

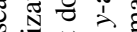

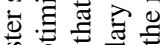

워융

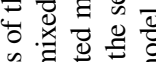

$\Leftrightarrow \exists$

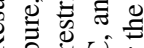

$m$ 훙

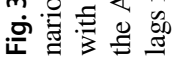


Table 3 Results of the raster search for the derivation of the optimal range of the distributed lag model

\begin{tabular}{|c|c|c|c|c|c|c|c|c|}
\hline \multirow[t]{4}{*}{ Species } & \multicolumn{4}{|l|}{ Pure } & \multicolumn{4}{|c|}{ Mixed } \\
\hline & \multicolumn{2}{|c|}{ Min. AIC } & \multicolumn{2}{|c|}{ Max. dev. expl. } & \multicolumn{2}{|c|}{ Min. AIC } & \multicolumn{2}{|c|}{ Max. dev. expl. } \\
\hline & (1) & (2) & (3) & (4) & (5) & (6) & (7) & (8) \\
\hline & Lags & Dev. expl. (\%) & Lags & Dev. expl. (\%) & Lags & Dev. expl. (\%) & Lags & dev. expl. (\%) \\
\hline Oak & 18 & 36.70 & 18 & - & 18 & 29.79 & 18 & - \\
\hline Pine & 19 & 24.56 & 19 & - & 24 & 29.69 & 25 & 29.70 \\
\hline Beech & 59 & 37.86 & 59 & - & 30 & 32.65 & 36 & 32.96 \\
\hline Spruce & 39 & 33.48 & 37 & 36.09 & 25 & 36.25 & 25 & - \\
\hline Beech & 59 & 35.25 & 59 & - & 36 & 39.74 & 36 & - \\
\hline Larch & 46 & 36.90 & 46 & - & 27 & 27.59 & 27 & - \\
\hline
\end{tabular}

The optimum number of lags was computed separately for each tree species and mixture scenario (pure, mixed). Optimization was separately performed for both pure beech stands. The optimum number of lags (columns 1, 5) was evaluated in terms of the minimum Akaike information criterion (min. AIC) among the different model candidates with different starting points in the distributed lag model, i.e., differing in the earliest month for which climate variables were considered. For models with a min. AIC, the deviance explained (columns 2,6) was also reported compared with a restricted model, which does not contain climate effects. Models with a higher deviance explained than those with the min. AIC existed, and the maximum possible deviance explained (columns 4,8) and associated number of lags (columns 3, 7) of the models were reported pure-stand scenarios, the period of influential climate was longest for beech, intermediate for larch and spruce, and relatively short for pine and oak.

\section{Age effects}

The smooth long-term effect of tree age represented by the additive term $g\left(\mathrm{Age}_{i}\right)$ in the linear predictor in Eq. 2 was evaluated as a multiplicative effect on the exponential scale (Fig. 4). For pine, spruce, and larch, the effect curves showed a continuously declining trend for both mixture scenario. The same applied to the curve for oak from the oak-pine plots. In contrast, the effect curves for beech had distinct maxima of between 15 and 30 years. The effect curve for tree-ring width data from the pure oak plots showed a local peak around the age of approximately 55 years. Curves of the individual "detrending" represented by the smooth term $f_{i}\left(\mathrm{Age}_{i}\right)$ in Eq. 1 and modeled by Duchon splines are presented in the online supplementary material (Fig. S1).

\section{Climate effects}

Once graphs with the resulting effect curves were plotted in the same way as by Nothdurft and Vospernik (2018), the illustrations became too complicated and were difficult to interpret. Hence, the corresponding figures showing the smooth response curves are provided as online supplementary material (Figs. S2-S7). For inclusion in the present paper, the information from the response curves was prepared in a more condensed form in Figs. 5 and 6. Consequently, the possible range of the effects associated with each of the monthly climate variables was calculated by the absolute difference between the minimum and maximum of the response predictions over the applied data range between the 2.5th and 97.5th percentiles.

Various shapes were possible with the penalized CRS, and it was indicated whether the respective curves were monotonically decreasing or increasing or whether they had a distinct global minimum or maximum. Because the tree species differed in their average annual productivity rates and with respect to their average sensitivity in response to the monthly climate variables, the plot symbol sizes were separately scaled for each species. If a common scale had been used instead, plot symbols would have become too small and would hardly have been visible for less productive tree species, such as oak or pine.

\section{Oak-pine triplet}

Summer temperatures were unfavorable for both oak and pine species and both mixture scenarios (Fig. 5). Although such negative effects were pronounced for oak in spring, pine benefited from warm spring temperatures. While the monthly temperature effects of the previous year were diverse for pine, oak benefited from higher spring and fall temperatures in the previous year. The period during which the monthly temperatures had negative influences was longer for oak in the oak-pine plots than for the pure oak plots. The opposite was true for pine, for which this particular period was shortened by mixing with oak. Compared with oak, pine benefited more from precipitation during the current year's spring. Although monthly precipitation during the previous year showed counteracting effects for oak, the growth of pine was facilitated by humid conditions during spring and 


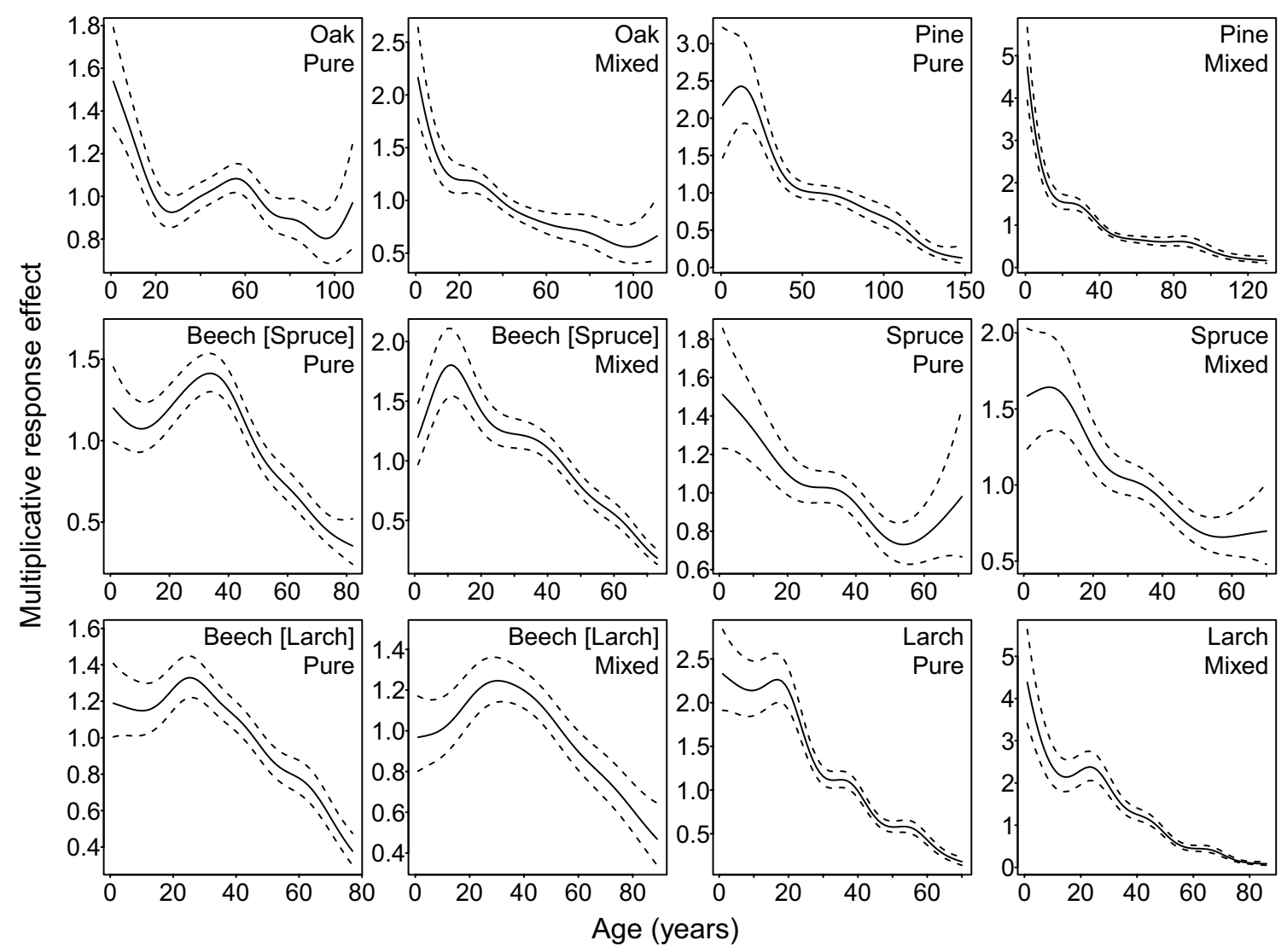

Fig. 4 Smooth long-term effect of tree age corresponding to the additive term $g\left(\mathrm{Age}_{i}\right)$ in the linear predictor in Eq. 2. The marginal effects were evaluated on the exponential scale acting as a multiplicative (not as an additive) effect on the response level. Dashed lines indicate the $90 \% \mathrm{CI}$

summer of the previous year, and these effects were more pronounced for pine on the oak-pine plots.

\section{Beech-spruce triplet}

Mixing shortened the period of influential climate for both beech and spruce. In comparison with the effects of monthly climate variables associated with the current and previous years for pure beech plots, the (positive/negative) signs of the effects were often reversed by the mixture scenario. Although temperature effects had a negative impact on pure beech plots, they were almost positive for beech mixed with spruce. The opposite occurred for spruce, and the positive temperature effects during the current growing season for the pure-stand conditions became negative in the mixture with beech. The negative effects of spring temperatures for the pure spruce plot became positive for spruce in the mixed beech-spruce plot. Similar phenomena were observed for the effects of monthly precipitation on the radial increment of beech. The effects of precipitation during the recent growing season changed from negative under the pure-stand scenario to positive in the mixture with spruce. Mixing likewise mitigated the negative effects of high precipitation during the previous summer. However, the negative effects of high precipitation during summer 2 years prior to the current growing season were further intensified by the mixture with spruce. The strong positive precipitation effects during the current growing season for spruce growth under pure-stand conditions were weakened by mixture with beech. The influence of precipitation during the summer and fall of the previous year changed from negative under pure-stand conditions to mostly positive in the mixture with beech. However, the influence of precipitation during the winter and spring in the year prior to the recent growing period changed from slightly positive under the pure-stand scenario to significantly negative in the mixture with beech.

\section{Beech-larch triplet}

Similar to its effect on the beech-spruce triplet, mixing has shortened the periods of influential monthly climate variables for the beech-larch triplet. In addition, the mixture with larch strengthened the effects of temperature on beech during the growing season and weakened the temperature effects during the dormant periods. The effects of monthly precipitation during the previous two vegetation periods 

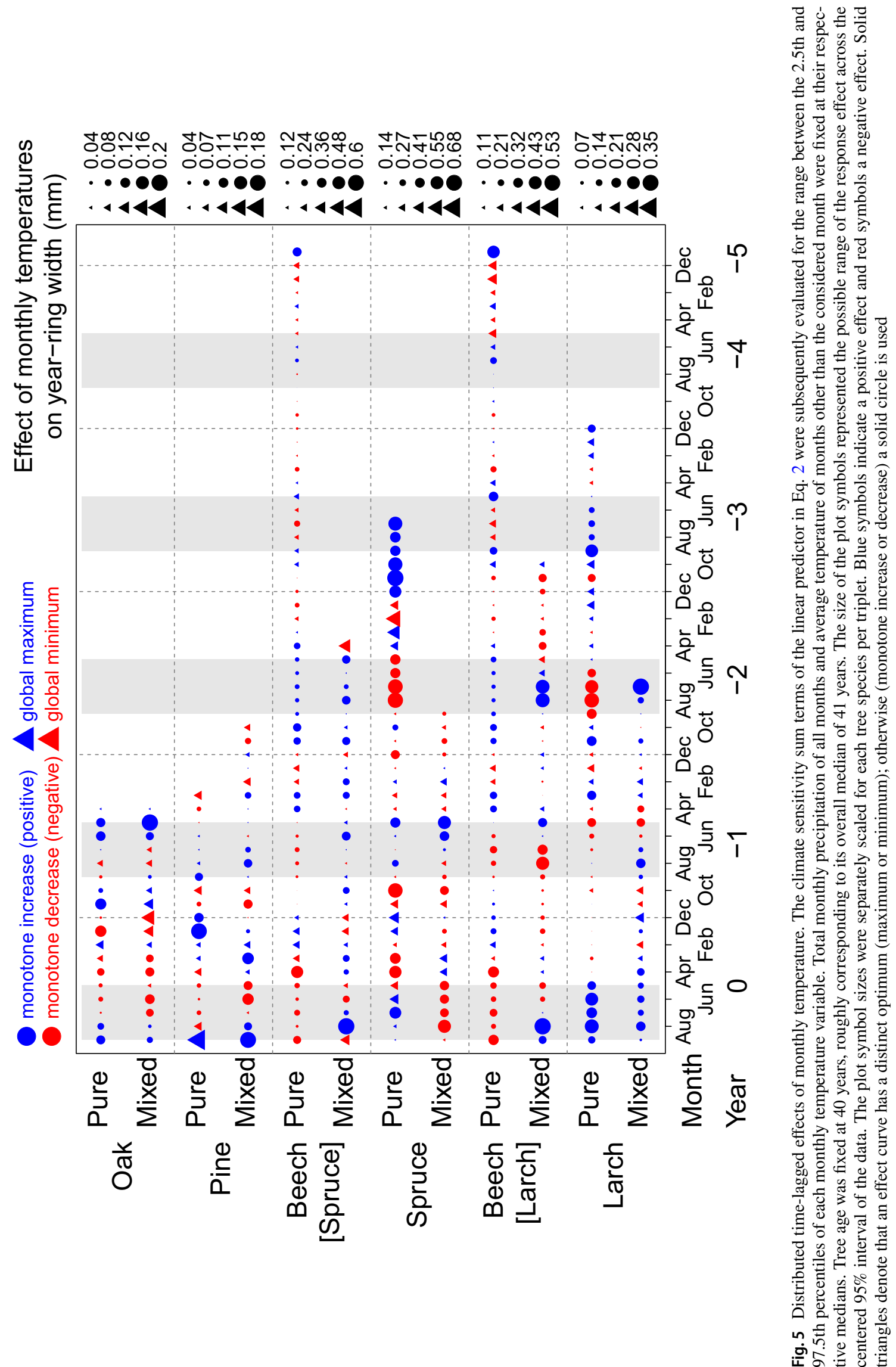

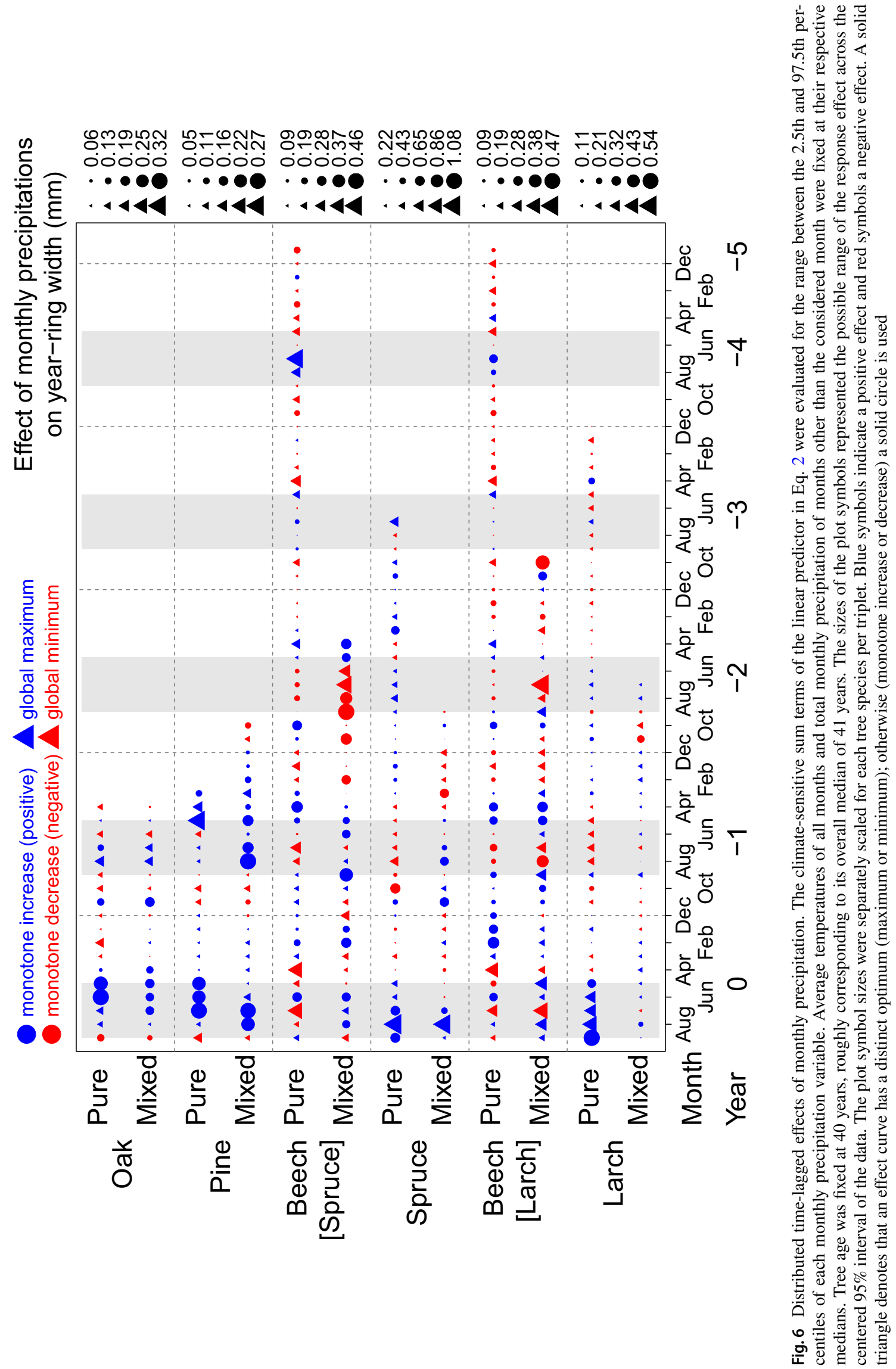
Table 4 Summary statistics of the predictions $(\mathrm{mm})$ of the distributed lag models for simulated climate sequences

\begin{tabular}{|c|c|c|c|c|c|c|c|c|c|c|c|c|c|c|c|}
\hline \multirow[t]{2}{*}{ Species } & \multirow[t]{2}{*}{ Mixture } & \multirow[t]{2}{*}{ Mean } & \multirow[t]{2}{*}{ Median } & \multirow[t]{2}{*}{ Min. } & \multicolumn{10}{|c|}{ Percentiles } & \multirow[t]{2}{*}{ Max. } \\
\hline & & & & & 0.5 & 2.5 & 5 & 10 & 25 & 75 & 90 & 95 & 97.5 & 99.5 & \\
\hline Oak & Pure & 1.25 & 1.24 & 0.61 & 0.73 & 0.82 & 0.88 & 0.96 & 1.09 & 1.39 & 1.55 & 1.64 & 1.71 & 1.94 & 2.46 \\
\hline Oak & Mixed & 1.01 & 1.01 & 0.51 & 0.58 & 0.66 & 0.72 & 0.78 & 0.89 & 1.12 & 1.24 & 1.31 & 1.41 & 1.75 & 2.13 \\
\hline Pine & Pure & 1.18 & 1.16 & 0.82 & 0.87 & 0.91 & 0.94 & 0.98 & 1.06 & 1.28 & 1.40 & 1.47 & 1.54 & 1.66 & 1.86 \\
\hline Pine & Mixed & 0.96 & 0.94 & 0.47 & 0.57 & 0.66 & 0.70 & 0.75 & 0.83 & 1.08 & 1.21 & 1.31 & 1.40 & 1.61 & 1.82 \\
\hline Beech & Pure & 2.59 & 2.43 & 0.65 & 1.04 & 1.25 & 1.39 & 1.56 & 1.93 & 3.08 & 3.80 & 4.35 & 4.82 & 6.02 & 8.27 \\
\hline Beech & Mixed & 2.21 & 2.10 & 0.86 & 1.07 & 1.24 & 1.36 & 1.48 & 1.75 & 2.52 & 3.04 & 3.46 & 3.95 & 4.97 & 6.97 \\
\hline Spruce & Pure & 2.96 & 2.75 & 0.79 & 1.14 & 1.44 & 1.59 & 1.79 & 2.18 & 3.49 & 4.38 & 5.06 & 5.65 & 7.05 & 15.21 \\
\hline Spruce & Mixed & 2.13 & 2.07 & 0.79 & 0.99 & 1.21 & 1.33 & 1.48 & 1.74 & 2.44 & 2.82 & 3.13 & 3.42 & 4.04 & 5.24 \\
\hline Beech & Pure & 2.52 & 2.42 & 0.95 & 1.20 & 1.40 & 1.52 & 1.69 & 2.00 & 2.93 & 3.48 & 3.89 & 4.19 & 5.09 & 6.48 \\
\hline Beech & Mixed & 2.42 & 2.37 & 1.09 & 1.35 & 1.57 & 1.68 & 1.83 & 2.08 & 2.70 & 3.04 & 3.29 & 3.55 & 4.09 & 4.94 \\
\hline Larch & Pure & 1.81 & 1.77 & 0.68 & 0.91 & 1.08 & 1.19 & 1.30 & 1.51 & 2.06 & 2.36 & 2.56 & 2.73 & 3.07 & 4.04 \\
\hline Larch & Mixed & 1.78 & 1.77 & 0.93 & 1.13 & 1.25 & 1.34 & 1.43 & 1.59 & 1.96 & 2.14 & 2.26 & 2.38 & 2.64 & 3.05 \\
\hline
\end{tabular}

Table 5 Changes in productivity, climate sensitivity, and resistance induced by mixing, evaluated by means of the predictions for simulated climate sequences

\begin{tabular}{|c|c|c|c|c|c|}
\hline \multirow[t]{2}{*}{ Species } & \multirow{2}{*}{$\begin{array}{l}\text { Relative change of } \\
\text { productivity (\%) }\end{array}$} & \multicolumn{2}{|c|}{ Climate sensitivity (CS) } & \multicolumn{2}{|l|}{ Resistance (Rs) } \\
\hline & & $\begin{array}{l}\text { Relative change of } \\
\text { absolute CS (\%) }\end{array}$ & $\begin{array}{l}\text { Change of relative CS } \\
\text { (percentage points) }\end{array}$ & $\begin{array}{l}\text { Relative change of } \\
\text { absolute Rs (\%) }\end{array}$ & $\begin{array}{l}\text { Change of relative Rs } \\
\text { (percentage points) }\end{array}$ \\
\hline Oak & -18.8 & -16.7 & 1.9 & -19.4 & -0.5 \\
\hline Pine & -18.2 & 17.1 & 22.9 & -27.7 & -9.0 \\
\hline Beech & -14.8 & -24.3 & -15.5 & -0.3 & 8.2 \\
\hline Spruce & -28.1 & -47.6 & -38.7 & -15.5 & 8.5 \\
\hline Beech & -4.2 & -28.9 & -28.5 & 12.2 & 9.5 \\
\hline Larch & -1.2 & -31.6 & -28.2 & 16.3 & 10.6 \\
\hline
\end{tabular}

The relative change in productivity was calculated as the relative percentage change of the average predicted annual radial increment. The relative change in the absolute climate sensitivity was evaluated as the relative percentage change in the absolute range of the $95 \%$ prediction interval. The change in the relative climate sensitivity (in relation to the corresponding average productivity) was provided as the difference in percentage points. The relative change in the absolute resistance was evaluated as the relative percentage change in the absolute lower limit of the $95 \%$ prediction interval (2.5th percentile). The change in the relative resistance was calculated as the difference in the relative resistance $(2.5$ th percentile in relation to the average prediction) in percentage points

were also intensified for beech. In contrast, the temperature effects for larch were slightly weakened by the mixture with beech, and the precipitation effects were even more strongly dampened.

\section{Predictions with simulated climate sequences}

It was examined whether the choice of 5000 simulations was sufficient to provide stable results. Calculations showed that the mean estimate became stationary after a few hundred simulations, and the $95 \%$ interval behaved stable after 2000 simulations (see Fig. S8 in the online supplementary material). Thus, the choice of 5000 simulations was appropriate.

Evaluation of the simulation results revealed that oak and pine, respectively, showed the lowest productivity in terms of average predicted annual radial increment, namely $1.25 \mathrm{~mm}$ and $1.18 \mathrm{~mm}$ for a 40 -year-old tree in a pure-stand scenario (Table 4). The average predicted productivity among the pure stands was highest for spruce $(2.96 \mathrm{~mm})$. The average predicted radial increment for beech was similar in both triplets: $2.59 \mathrm{~mm}$ in the pure stand of the beech-spruce triplet and $2.52 \mathrm{~mm}$ in the pure stand of the beech-larch triplet. The results revealed that mixing significantly lowered the productivity of spruce $(-28 \%)$, oak $(-19 \%)$, pine $(-18 \%)$, and beech (beech-spruce, $-15 \%$; beech-larch, $-4 \%$ ), whereas the productivity of larch remained almost constant $(-1 \%)$ (Table 5 and Fig. 7 with corresponding Table S1).

From an absolute perspective, species mixing increased the climate sensitivity of pine $(+17 \%)$ and led to reduced absolute climate sensitivities of the other tree species. The 


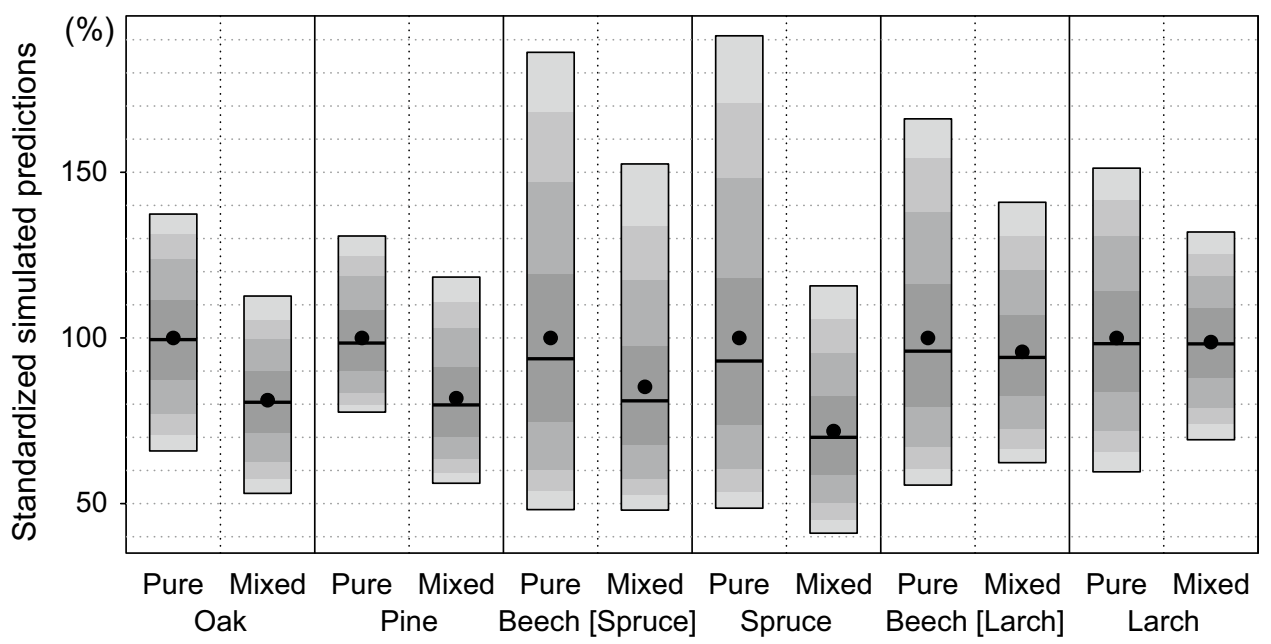

Fig. 7 Predictions with distributed lag models for simulated climate sequences. Predictions were standardized for each tree species by the average prediction for the corresponding pure-stand scenario, i.e., per species, and the simulations were divided by the average of the respective pure-stand scenarios. Black solid circles indicate the mean, black horizontal segments the median, the light-gray area the range between the 2.5 th and 97.5 th percentiles, the medium-light-gray area the range between the 5th and 95th percentiles, the medium-dark-gray area the range between the 10th and 90th percentiles, and the darkgray area the range between the 25 th and 75 th percentiles reduction was strongest for spruce $(-48 \%)$ and moderate for oak $(-17 \%)$. Climate sensitivities of both species from the beech-larch triplet were lowered by almost the same relative amount (beech, $-29 \%$; larch, $-32 \%$ ). The climate sensitivity of beech was not reduced as severely $(-24 \%)$ by the mixture with spruce.

When the productivity levels and their changes were considered from a relative perspective, the relative climate sensitivity of pine increased through mixing, whereas that of oak increased only slightly. Despite their decreased productivity, the lowered climate sensitivities of the other tree species were maintained under the premise of relative analysis.

From an absolute perspective, the lower limit of the prediction interval for pine was severely reduced $(-28 \%)$ by the mixture with oak. The lower limits of the oak models were also strongly reduced (-19\%), but this reduction was as strong as that of the mean productivity. Species mixing did not influence the lower limit of the beech model predictions for the beech-spruce triplet, but a reduction occurred in the spruce models $(-16 \%)$. In contrast, the lower limits of predictions for beech and larch from the corresponding triplet increased in the mixture scenario (beech, $+12 \%$; larch, $+16 \%)$. However, if the lower prediction limit was expressed relatively in relation to average productivity, only the relative resistance of pine was negatively affected by the mixture scenario. The relative resistance of oak remained almost unchanged, and that of the other tree species increased by $8-11$ percentage points.

The upper limits of the prediction intervals decreased for all tree species. The reductions were smaller for the pine models or as large as the relative change in mean productivity rate for the oak models. The upper prediction limit was strongly reduced for beech (beech-spruce triplet) and even stronger for spruce. The former reduction was only slightly stronger than the mean productivity change of beech, but the latter was much stronger. Finally, the upper limits of the prediction intervals were significantly reduced for both species from the beech-larch plot.

\section{Diagnostics}

The smoothed scatterplots of the standardized residuals versus predictions (Fig. 8) show that the residuals behaved well, with no evidence of a trend. In addition, the smoothed scatterplots of predictions versus observations (Fig. 9) show that the densities of the points were independently and closely distributed around the reference lines with zero intercepts and slopes of one. The biases of the models ranged from a minimum of $0.0004 \mathrm{~mm}$, obtained with the beech model for the pure-stand scenario of the beech-larch triplet, to a maximum of $0.0119 \mathrm{~mm}$, obtained with the pure spruce model (Table 6). Thus, model biases were considered negligible. The root mean square errors (RMSEs) of the models were also relatively small, with a minimum RMSE of 0.265 , obtained with the pure oak model, and a maximum of 0.581 , obtained with the pure spruce model. The adjusted $R^{2}$ was relatively high for all models. The pure oak model had the smallest adjusted $R^{2}$ of 0.784 , whereas the larch model for the mixed-stand scenario had the highest $R^{2}$ of 0.925 . The total deviance explained was relatively high for all models 

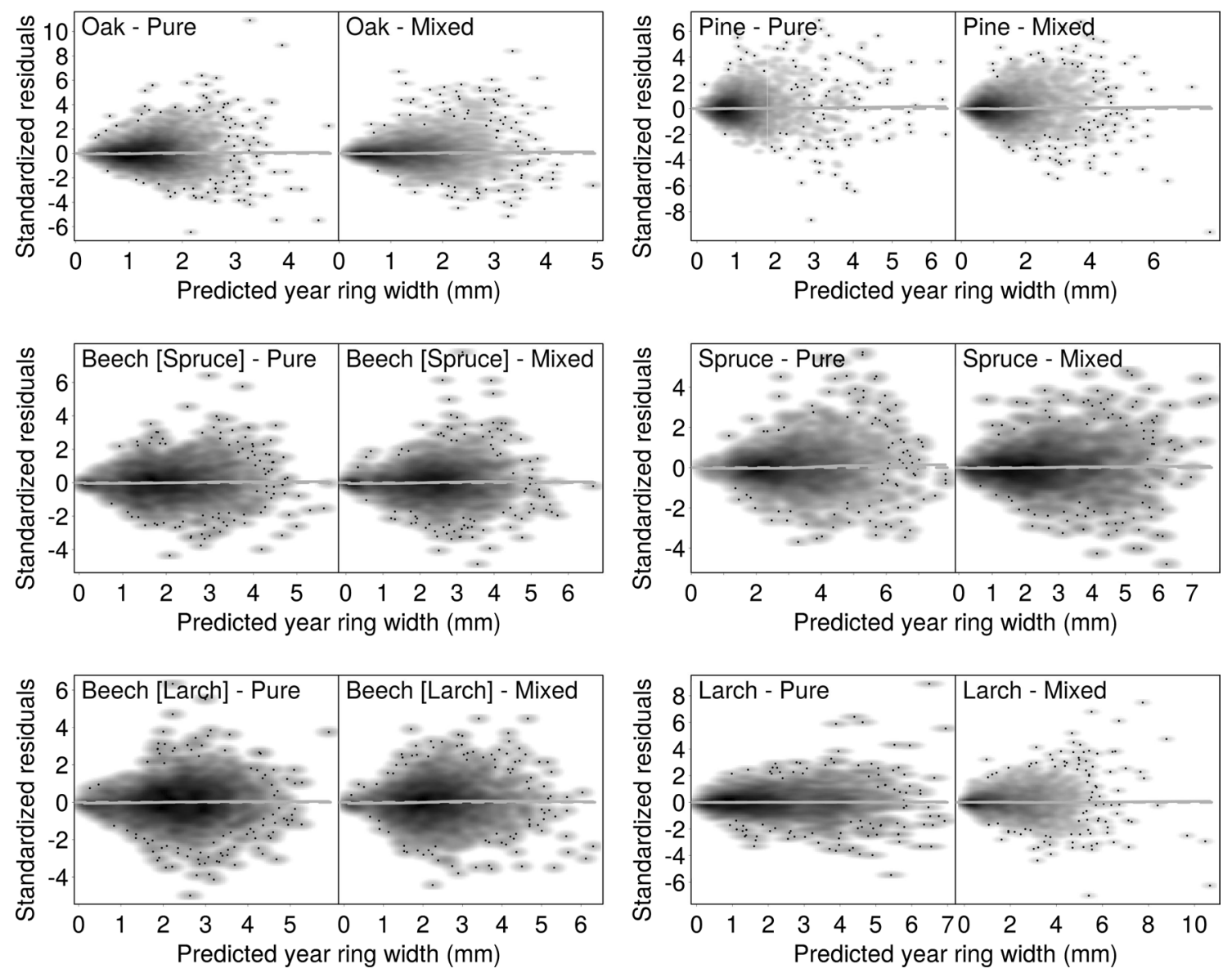

Fig. 8 Diagnostic plots. Smoothed densities of the corresponding scatter plots were derived through two-dimensional kernel density estimates of standardized residuals versus predicted tree-ring widths.

and ranged from $83.2 \%$, obtained with the oak model in the pure-stand scenario, to $94.8 \%$, obtained with the larch model under the mixed-stand scenario.

The pine model in the pure-stand scenario had the lowest relative amount of effective degrees of freedom (EDF); it required $435 \mathrm{EDF}$ with 4606 observations (see Hastie and Tibshirani 1990 for further details on the computation of EDF). The spruce model in the mixed-stand scenario required $295 \mathrm{EDF}$ with 1746 observations. The largest relative number of EDF was consumed by the Duchon spline smoothers used for individual "detrending." These individual smooth components accounted for between $82 \%$ (pure spruce) and $89 \%$ (pure oak) of the models' total EDF. A minimum absolute number of 242.9 EDF was used with the spruce model in the pure-stand scenario and a maximum absolute number of 495.1 EDF with the oak model in the pure-stand scenario. The climate-related smooth terms of the distributed lag models comprised a minimum of $41 \mathrm{EDF}$ (pure larch) and maximum of 50 EDF (pure oak). Finally,

Light-gray dashed line indicates the zero-reference, the light-gray solid line the local polynomial regression fit, and small dots the outliers

the smooth component for the global age effects had EDFs of between 5.4 and 8.6.

In summary, the regression models were regarded as well specified and provided a good fit for the data.

\section{Discussion}

\section{Temporal range of influential climate conditions}

The results from the optimization of the lag ranges revealed that species mixing generally reduced the temporal range of climate influences, except for pine and oak. Species mixing therefore suppresses time-lagged climate effects from the past that would otherwise influence the same tree species in pure-stand situations. This is probably because the regular response mechanisms operating in pure-stand scenarios experienced interference from the different ecological requirements of the associated tree species in a mixed-stand scenario. This hypothesis is supported by the findings for 


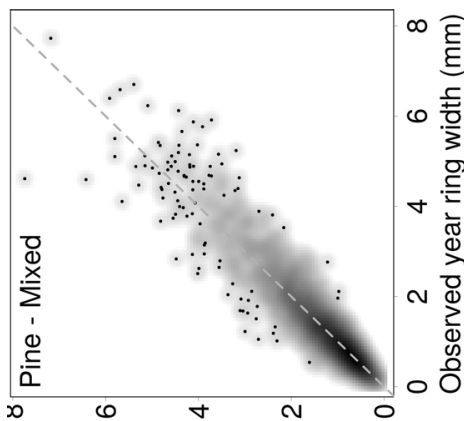

(шس) чıр!м бu!ı леәК рәเэрәдd

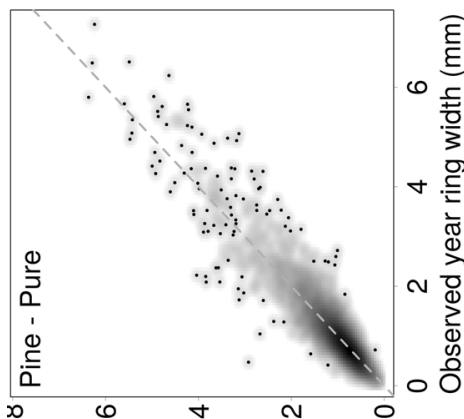

(mu) чıр!м 6u!ı леәК рәюэрәлд

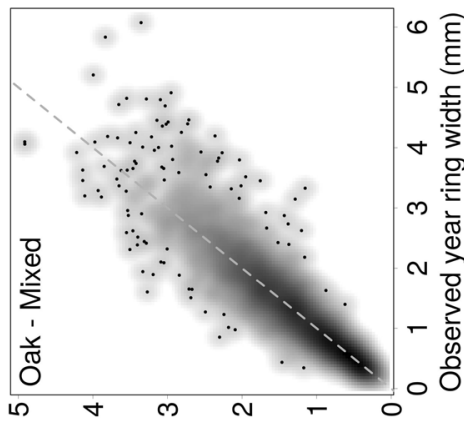

(mш) чІр!м Би!л деәК рәээ!рәлd

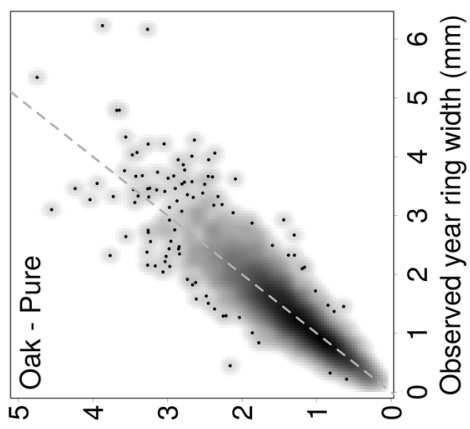

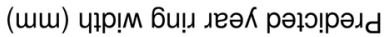

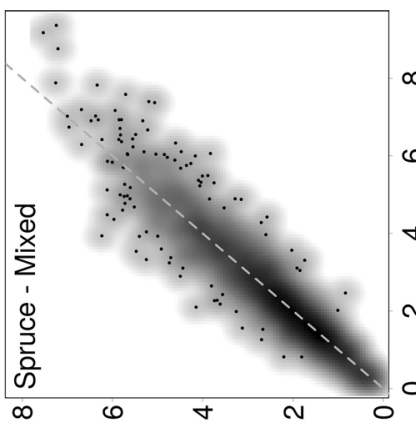

(mu) чıр!м би!ı деәк рәџэрәлd

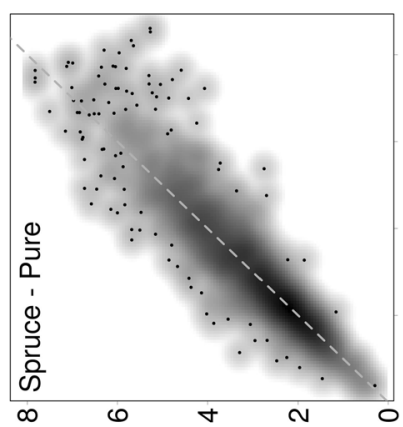

(uш) чıр!м би!ı деәК рәээ!рәлd

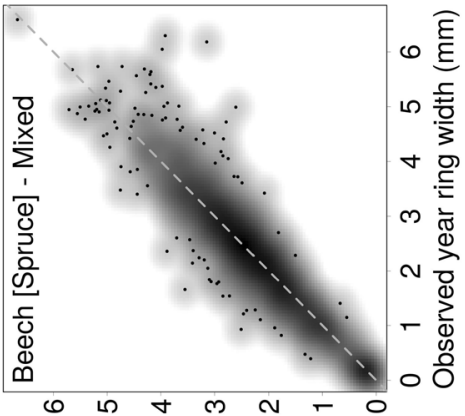

(mw) чıр!м бu!n גеәк рәэо!рәлd

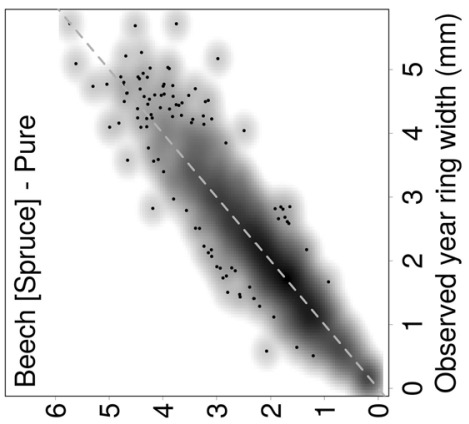

(um) чıр!м бu!̣ גеәК рәเо!рәлд
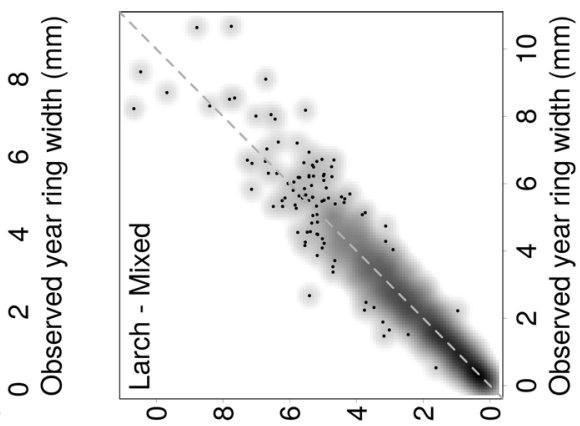

(шіш) чıр!м би!ı леәк рәюэрәлд

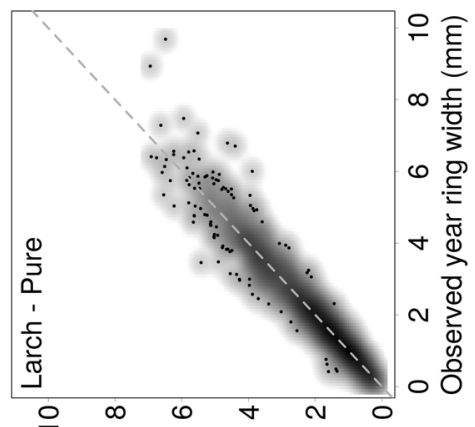

(uш) чıр!м бu!ı деәК рәюэррәлд

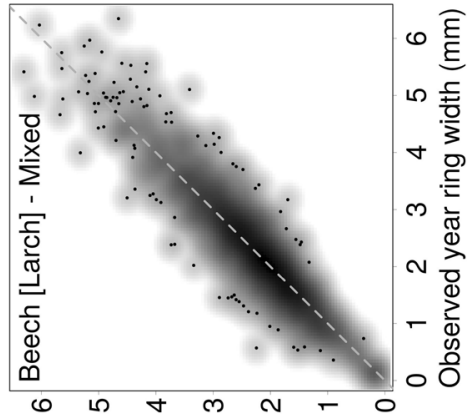

(шس) чเр!м бu!ı леәК рәџэрәлd

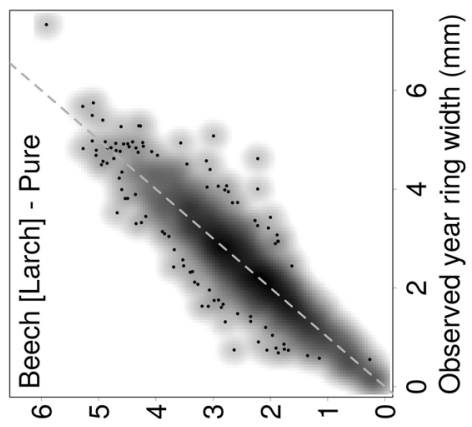

(шس) чұр!м би!ı леәК рәюэрәлд 
Table 6 Summary diagnostics of distributed lag models

\begin{tabular}{|c|c|c|c|c|c|c|c|c|c|c|c|c|}
\hline \multirow{2}{*}{$\begin{array}{l}\text { Species } \\
\text { Mixture }\end{array}$} & \multicolumn{2}{|l|}{ Oak } & \multicolumn{2}{|l|}{ Pine } & \multicolumn{2}{|c|}{ Beech (Spruce) } & \multicolumn{2}{|l|}{ Spruce } & \multicolumn{2}{|c|}{ Beech (Larch) } & \multicolumn{2}{|l|}{ Larch } \\
\hline & Pure & Mixed & Pure & Mixed & Pure & Mixed & Pure & Mixed & Pure & Mixed & Pure & Mixed \\
\hline No. of observations & 5170 & 3914 & 4606 & 4400 & 2128 & 2135 & 1769 & 1746 & 2100 & 2490 & 1951 & 2208 \\
\hline Residual df. & 4616 & 3464 & 4171 & 3964 & 1821 & 1794 & 1471 & 1451 & 1793 & 2157 & 1639 & 1898 \\
\hline Dev. expl. & 0.836 & 0.877 & 0.832 & 0.876 & 0.887 & 0.905 & 0.860 & 0.901 & 0.869 & 0.863 & 0.941 & 0.948 \\
\hline Adj. $R^{2}$ & 0.784 & 0.813 & 0.831 & 0.859 & 0.859 & 0.858 & 0.806 & 0.868 & 0.837 & 0.838 & 0.923 & 0.925 \\
\hline Bias (mm) & 0.0033 & 0.0073 & 0.0033 & 0.0043 & 0.0012 & 0.0026 & 0.0119 & 0.0041 & 0.0004 & 0.0006 & 0.0011 & 0.0027 \\
\hline RMSE (mm) & 0.265 & 0.324 & 0.283 & 0.326 & 0.342 & 0.389 & 0.581 & 0.480 & 0.378 & 0.378 & 0.359 & 0.390 \\
\hline \multicolumn{13}{|c|}{ Effective degrees of freedom } \\
\hline$f_{i}($ Age $)$ & 495.1 & 396.5 & 380.3 & 379.7 & 251.7 & 284.4 & 242.9 & 243.4 & 251.4 & 277.3 & 260.8 & 253.2 \\
\hline$g$ (Age) & 7.9 & 7.1 & 7.4 & 8.4 & 6.8 & 7.9 & 5.9 & 6.0 & 7.1 & 5.4 & 8.6 & 8.6 \\
\hline$\sum \gamma($ Temp, lag $)$ & 14.7 & 11.8 & 13.2 & 14.6 & 15.7 & 15.5 & 15.4 & 15.1 & 15.6 & 15.4 & 14.7 & 14.0 \\
\hline$\sum \delta(\operatorname{Prec}, \mathrm{lag})$ & 3.9 & 3.8 & 3.5 & 1.7 & 3.9 & 3.9 & 3.7 & 1.0 & 3.7 & 2.9 & 2.4 & 3.7 \\
\hline$\sum \kappa($ Temp, Prec, lag) & 31.1 & 30.1 & 30.1 & 30.9 & 27.9 & 28.7 & 28.6 & 28.8 & 27.8 & 30.9 & 24.1 & 29.2 \\
\hline
\end{tabular}

the oak-pine triplet that proved to be an exception. Oak and pine showed similar patterns in their responses to monthly climate variables across the entire lag range. Consequently, the optimized range of the time lag models was almost equal under pure-stand scenarios and did not change under mixedstand scenarios for either species. In contrast, the associated tree species from the other triplets often showed an opposite response to the same climate variables, especially with respect to the effects of monthly temperature. Hence, the contrasting behavior among the associated tree species under a mixed-stand scenario might override the effects of climate conditions in the more distant past.

The results from the analysis of the marginal effects further revealed that mutual interactions might exist between the species in a mixed-stand scenario. This was indicated by sign reversals of the marginal climate effects, which were induced by mixture with another tree species. This phenomenon occurred for both species in the beech-spruce and beech-larch triplets.

\section{Productivity}

Species mixing lowered the productivity of single trees on the study sites in Lower Austria. These results are in contrast with the findings from existing studies in that species mixing generally leads to enhanced productivity (Pretzsch 2009; Pretzsch et al. 2010, 2013; Condés et al. 2013; Pretzsch et al. 2015). However, while these latter studies focused on the analysis of stand-level productivity, the present study focused on that of individual trees. Lowered productivity of single trees does not necessarily mean that the same results hold for a complete forest stand, as species mixing might positively effect stand-level productivity through vertical layering of species with different shade tolerance and thereby allowing for higher stem densities (Pretzsch et al. 2010, 2013). Thus, further work is required to enhance the distributed lag models presented here by additional covariates, such as the (relative) dbh or structural measures reflecting inter-tree competition to provide an appropriate approach to the upscaling of single-tree increment predictions.

Comprehensive trials have been conducted to incorporate such size-related effects, e.g., in terms of the current individual dbh associated with each tree-ring measurement. However, the sample size of only 30 tree-ring series per plot proved to be too small to consider additional tree size effects. It is therefore expected that additional data will have to be collected for future predictions that can be upscaled to the stand level. Findings from our trials also suggest that the presented model framework may hinder the additional modeling of size effects, as the individual Duchon spline smoothers implicitly account for differences in tree sizes and their changes over time. Consequently, the Duchon spline component should compete with further size-related effects that are simultaneously modeled.

\section{Climate sensitivity}

The absolute range of possible annual radial increments, i.e., absolute climate sensitivity, was reduced for all tree species, except for pine, which showed an increased absolute climate sensitivity through species mixing. These results, obtained from an absolute perspective, differed only slightly from those achieved by a relative analysis. Thus, the relative range of possible annual radial increments in relation to the average expectations for each species and mixture scenario, i.e., the relative climate sensitivity, increased for pine and slightly increased for oak. 
This increase occurred because the lower limit of the predicted increments for pine was severely reduced through the mixture with oak, whereas the upper potential increment was only slightly reduced (Table 4). The maximum prediction for pine remained nearly constant between the pure- and mixedstand scenarios. As suggested by our findings, oak and pine have similar requirements with respect to climate conditions in the study sites. The mixture with oak might have induced higher inter-specific competition during drought periods and when available soil water was limited, and, vice versa, competition became less relevant under more favorable climate conditions and when water resources were abundant.

The other tree species showed reduced relative climate sensitivity. Hence, the findings of existing studies (Merlin et al. 2015; Toïgo et al. 2015; Bonal et al. 2017) contradict the results of the present study, as a mixture effect on the climate sensitivity has not been revealed in the context of oak-pine mixtures. However, the findings of this study are supported by Metz et al. (2016), who also found that beech has a lowered climate sensitivity in an allo-specific environment. Comparable results regarding the other examined mixture compositions are currently lacking, but Cavin et al. (2013) found that the climate sensitivity of beech was reduced in coexistence with oak. The present study thus provides new insights into the possible effects of species mixing on the climate-related response of forest trees in terms of modified annual radial stem increments.

Lower climate sensitivity can be interpreted as a reduced reaction capacity to extreme climate conditions. Theoretically, the tolerance range could be reduced from both directions. More specifically, productivity can be moderated when climate conditions are favorable, or growth recession can be mitigated when climate conditions are unfavorable. Furthermore, it is possible that mixing acts simultaneously via both mechanisms. As hypothesized by Pretzsch et al. (2013), and according to the stress-gradient hypothesis (Callaway 2007; Pugnaire et al. 2011; Soliveres et al. 2011; He et al. 2013; Michalet et al. 2014), the ecological mechanisms behind a mitigated growth decline may rely on symbiotic interactions during stress scenarios, whereas inter-species competition becomes more relevant under better environmental conditions, which may subsequently hinder the trees from fulfilling their potential productivity. However, the findings of the present study are contrary to this theory in that the climate sensitivity of pine increased with the mixture with oak in the relatively dry sites in Maissau, whereas on the more favorable sites in Kreisbach, climate sensitivity decreased for beech, spruce, and larch.

The sign reversals of the marginal climate effects indicated that strong mutual interactions exist between tree species in a mixed-stand scenario. These interactions can simultaneously act in both directions and have both positive and negative effects. Besides the lowered productivity rates, species mixing has a facilitative effect, especially in the favorable sites, as climate sensitivity is significantly mitigated (see also Holmgren and Scheffer (2010) and Holmgren et al. (2012) for facilitative effects under mild environments).

\section{Resistance}

The results of the present study showed that reduced climate sensitivity does not necessarily imply enhanced resistance, and vice versa. Among the species that showed a decreased absolute climate sensitivity through mixing, the absolute resistance was only increased for beech and larch in their triplet. In contrast, pine showed a decreased absolute resistance given that its absolute climate sensitivity increased. However, if resistance and climate sensitivity are expressed in terms of relative measures in relation to the average expectations, resistance was increased for beech in both triplets and for spruce and larch, which showed an altogether lowered relative climate sensitivity. In addition, the relative resistance of pine consequently decreased, while its relative climate sensitivity was increased through mixing. In terms of relative measures, oak behaved indifferently with respect to mixing effects.

Hitherto, broad evidence has been lacking for the possible effects of species mixing on the resistance of forest trees, especially with respect to the mixture scenarios examined in this study. These results may be consistent with those of Schäfer et al. (2017) in that the resistance of beech likely increased through the mixture with spruce in sites with a high soil water holding capacity.

Among all examined mixture scenarios, the oak-pine composition had the most unfavorable influence on the relative resistances of the tree species involved. While the relative resistance of pine decreased, it remained constant for oak. The explanation for this phenomenon is that both species possess similar patterns in their response to time-lagged monthly climate variables. This means that both species behave synchronously in terms of their annual stem biomass accumulation under given climate conditions. Hence, spatial cohabitation of oak and pine results in strong inter-species competition for restricted resources, which amplifies stress under unfavorable climate conditions. The opposite may hold true for the other mixture scenarios examined, which consistently resulted in enhanced relative resistances. The species in the beech-spruce and beech-larch triplets showed more pronounced differences with respect to marginal climate effects across the entire lag range. Thus, the diversification of the ecological requirements of the different tree species has facilitated their coexistence.

It must be stated that the present research is very much a case study, as the empirical analysis was restricted to Lower Austrian sites with a total of 12 sampling plots and four 
triplets covering three species mixture scenarios. Thus, the findings cannot be uncritically adopted for other sites in Austria. However, the present study is embedded within a European-wide project named 'REFORM' (http://www. reform-mixing.eu/). The aim of REFORM is to develop mixed-species forest management options that will ensure increased resilience and a lowered risk in the context of possible climate change. The major goals of the present work were rather to provide insights into the mechanisms behind the climate sensitivity of single-tree productivity rates and to propose a modern statistical framework that is able to properly address the underlying stochastic processes.

\section{Conclusions}

Species mixing generally lowered the productivity rates in terms of annual radial stem increment of the tree species examined on the selected Lower Austrian sites. The oak-pine mixture behaved differently than beech-spruce or beech-larch, in that the relative climate sensitivity of pine increased, whereas its relative resistance decreased through mixture. The same trend, but more weakly expressed, held for oak. Consequently, the mixing of oak and pine was unfavorable for both their productivity and resistance at the individual tree level. In contrast, the relative climate sensitivity of the other examined tree species was reduced throughout as a consequence of the mixed-stand scenarios. However, as the average productivity level changes by mixing, it is essential to distinguish between absolute and relative perspectives when a mixture-induced change in resistance is being evaluated. Hence, when resistance was calculated relatively, it increased for all corresponding tree species of the beech-spruce and beech-larch triplets. However, if calculated absolutely, the resistance of spruce was decreased by mixing, whereas the absolute resistance of beech was almost unaffected. As an implication for the silvicultural management of mixed forest stands, different species should be kept in spatially segregated patches to reduce possible counteracting effects that might be induced by the species mixture (Kelty 2006).

The novel statistical framework of penalized regression splines for a distributed lag model was capable of representing the complex nonlinear effects of climate variables and their smooth development across a series of time lags. By using this inferential technique for predicting conditional expectations, seemingly contradictory climate-related effects, which likely hinder a sound inference when forest tree resistance is evaluated via observed productivity changes, can be accounted for. Compared to a traditional dendrochronological approach, the presented model approach is parsimonious in light of the consumption of degrees of freedom. With the presented approach, a high number (several thousands) of residual degrees of freedom remained. If a single series of averaged index values, i.e., "mean chronology," were derived according to traditional dendrochronological techniques, such a mean chronology would have provided a maximum of 140 observations for the pine data in Maissau.

Acknowledgements Open access funding provided by University of Natural Resources and Life Sciences Vienna (BOKU). This study was supported by the project REFORM under the umbrella of the ERANET project Sumforest and was locally financed by the Austrian Federal Ministry of Agriculture, Forestry, Environment and Water Management under project number 101199. The authors are grateful to Clemens Wassermann, Christoph Gollob, Angela Kumer, and Andreas Tockner for their careful field and laboratory work.

Open Access This article is distributed under the terms of the Creative Commons Attribution 4.0 International License (http://creativeco mmons.org/licenses/by/4.0/), which permits unrestricted use, distribution, and reproduction in any medium, provided you give appropriate credit to the original author(s) and the source, provide a link to the Creative Commons license, and indicate if changes were made.

\section{References}

Akaike $H$ (1973) Information theory as an extension of the maximum likelihood principle. In: Petrov BN, Csaksi F (eds) 2nd international symposium on information theory. Akademiai Kiado, Budapest, pp 267-281

Albert M, Schmidt M (2010) Climate-sensitive modelling of siteproductivity relationships for Norway spruce (Picea abies (L.) Karst.) and common beech (Fagus sylvatica L.). For Ecol Manag 259(4):739-749

Allen CD, Macalady AK, Chenchouni H, Bachelet D, McDowell N, Vennetier M, Kitzberger T, Rigling A, Breshears DD, Hogg EH, Gonzalez P, Fensham R, Zhang Z, Castro J, Demidova N, Lim J-H, Allard G, Running SW, Semerci A, Cobb N (2010) A global overview of drought and heat-induced tree mortality reveals emerging climate change risks for forests. For Ecol Manag 259(4):660-684

Bauhus J, Forrester DI, Gardiner B, Jactel H, Vallejo R, Pretzsch H (2017) Ecological stability of mixed-species forests. In: Pretzsch H, Forrester DI, Bauhus J (eds) Mixed-species forests: ecology and management. Springer, Berlin, pp 337-382

Beniston M, Stephenson DB, Christensen OB, Ferro CA, Frei C, Goyette S, Halsnaes K, Holt T, Jylhä K, Koffi B, Palutikof J (2007) Future extreme events in European climate: an exploration of regional climate model projections. Clim Change 81(1):71-95

Böhm R, Auer I, Schöner W, Ganekind M, Gruber C, Jurkovic A, Orlik A, Ungersböck M (2009) Eine neue Webseite mit instrumentellen Qualitäts-Klimadaten für den Grossraum Alpen zurück bis 1760 . Wiener Mitteilungen 216:7-20

Bonal D, Pau M, Toigo M, Granier A, Perot T (2017) Mixing oak and pine trees does not improve the functional response to severe drought in central French forests. Ann For Sci 74:72

Callaway RM (2007) Positive interactions and interdependence in plant communities. Springer, Dordrecht, p 404

Cavin L, Jump AS (2017) Highest drought sensitivity and lowest resistance to growth suppression are found in the range core of the tree Fagus sylvatica $\mathrm{L}$. not the equatorial range edge. Glob Change Biol 23(1):362-379 
Cavin L, Mountford EP, Peterken GF, Jump AS (2013) Extreme drought alters competitive dominance within and between tree species in a mixed forest stand. Funct Ecol 27(6):1424-1435

Clark JS, Iverson L, Woodall CW, Allen CD, Bell DM, Bragg DC, D'Amato A, Davis FW, Hersh MH, Ibanez I, Jackson ST, Matthews S, Pederson N, Peters M, Schwartz MW, Waring KM, Zimmermann NE (2016) The impacts of increasing drought on forest dynamics, structure, and biodiversity in the United States. Glob Change Biol 22(7):2329-2352

Condés S, Del Rio M, Sterba H (2013) Mixing effect on volume growth of Fagus sylvatica and Pinus sylvestris is modulated by stand density. For Ecol Manag 292:86-95

Conte E, Lombardi F, Battipaglia G, Palombo C, Altieri S, La Porta N, Marchetti M, Tognetti R (2018) Growth dynamics, climate sensitivity and water use efficiency in pure vs. mixed pine and beech stands in Trentino (Italy). For Ecol Manag 409:707-718

Dănescu A, Kohnle U, Bauhus J, Sohn J, Albrecht AT (2018) Stability of tree increment in relation to episodic drought in uneven-structured, mixed stands in southwestern Germany. For Ecol Manag 415-416:148-159

Dittmar C, Zech W, Elling W (2003) Growth variations of common beech (Fagus sylvatica L.) under different climatic and environmental conditions in Europe-a dendrochronological study. For Ecol Manag 173(1-3):63-78

Douglass AE (1936) Climatic cycles and tree-growth, vol 3. Carnegie Institution of Washington, Washington

Duchon J (1977) Splines minimizing rotation-invariant semi-norms in Sobolev spaces. In: Shemp W, Zeller K (eds) Construction theory of functions of several variables. Springer, Berlin, pp $85-100$

Ehbrecht M, Schall P, Ammer C, Seidel D (2017) Quantifying stand structural complexity and its relationship with forest management, tree species diversity and microclimate. Agric For Meteorol 242:1-9

Fotelli MN, Nahm M, Radoglou K, Rennenberg H, Halyvopoulos G, Matzarakis A (2009) Seasonal and interannual ecophysiological responses of beech (Fagus sylvatica L.) at its south-eastern distribution limit in Europe. For Ecol Manag 257(3):1157-1164

Fritts HC (1976) Tree rings and climate. Academic Press, London, p 567

Gobiet A, Kotlarski S, Beniston M, Heinrich G, Rajczak J, Stoffel M (2014) 21st century climate change in the European Alps-a review. Sci Total Environ 493:1138-1151

Goisser M, Geppert U, Rötzer T, Paya A, Huber A, Kerner R, Bauerle T, Pretzsch H, Pritsch K, Häberle KH, Matyssek R, Grams TEE (2016) Does belowground interaction with Fagus sylvatica increase drought susceptibility of photosynthesis and stem growth in Picea abies? For Ecol Manag 375:268-278

Härdtle W, Niemeyer T, Assmann T, Aulinger A, Fichtner A, Lang A, Leuschner C, Neuwirth B, Pfister L, Quante M, Ries C, Schuldt A, von Oheimb G (2013) Climatic responses of treering width and $\Delta^{13} \mathrm{C}$ signatures of sessile oak (Quercus petraea Liebl.) on soils with contrasting water supply. Plant Ecol 214(9):1147-1156

Hastie TJ, Tibshirani RJ (1990) Generalized additive models. Chapman $\&$ Hall/CRC, New York, p 335

He Q, Bertness MD, Altieri AH (2013) Global shifts towards positive species interactions with increasing environmental stress. Ecol Lett 16(5):695-706

Holmgren M, Scheffer M (2010) Strong facilitation in mild environments: the stress gradient hypothesis revisited. J Ecol 98(6):1269-1275

Holmgren M, Gómez-Aparicio L, Quero JL, Valladares F (2012) Non-linear effects of drought under shade: reconciling physiological and ecological models in plant communities. Oecologia 169(2):293-305
Jacob D, Petersen J, Eggert B et al (2014) EURO-CORDEX: new high-resolution climate change projections for European impact research. Reg Environ Change 14(2):563-578

Johnson DH (1999) The insignificance of statistical significance testing. J Wildl Manag 63(3):763-772

Kelty MJ (2006) The role of species mixtures in plantation forestry. For Ecol Manag 233(2-3):195-204

Knoke T (2017) Economics of mixed forests. In: Pretzsch H, Forrester DI, Bauhus J (eds) Mixed-species forests: ecology and management. Springer, Berlin, pp 545-577

Knoke T, Ammer C, Stimm B, Mosandl R (2008) Admixing broadleaved to coniferous tree species: a review on yield, ecological stability and economics. Eur J For Res 127(2):89-101

Lebourgeois F, Cousseau G, Ducos Y (2004) Climate-tree-growth relationships of Quercus petraea Mill. stand in the Forest of Bercé ("Futaie des Clo", Sarthe, France). Ann For Sci 61:361-372

Lévesque M, Rigling A, Bugmann H, Weber P, Brang P (2014) Growth response of five co-occurring conifers to drought across a wide climatic gradient in Central Europe. Agric For Meteorol 197:1-12

Levin SA (2009) The Princeton guide to ecology. Princeton University Press, Princeton, p 848

Linderholm HW (2001) Climatic influence on Scots pine growth on dry and wet soils in the Scandinavian mountains interpreted from tree-ring widths. Silva Fenn 35(4):415-424

Linderholm HW, Linderholm K (2004) Age-dependent climate sensitivity of Pinus sylvestris L. in the central Scandinavian Mountains. Boreal Environ Res 9:307-317

Lindner M, Maroschek M, Netherer S, Kremer A, Barbati A, GarciaGonzalo J, Seidl R, Delzon S, Corona P, Kolström M, Lexer MJ, Marchetti M (2010) Climate change impacts, adaptive capacity, and vulnerability of European forest ecosystems. For Ecol Manag 259(4):698-709

Martínez-Vilalta J, López BC, Loepfe L, Lloret F (2012) Stand- and tree-level determinants of the drought response of Scots pine radial growth. Oecologia 168(3):877-888

Merlin M, Perot T, Perret S, Korboulewsky N, Valler P (2015) Effects of stand composition and tree size on resistance and resilience to drought in sessile oak and Scots pine. For Ecol Manag 339:22-33

Metz J, Annighöfer P, Schall P, Zimmermann J, Kahl T, Schulze E-D, Ammer C (2016) Site-adapted admixed tree species reduce drought susceptibility of mature European beech. Glob Change Biol 22(2):903-920

Michalet R, Le Bagousse-Pinguet Y, Maalouf J-P, Lortie C (2014) Two alternatives to the stress gradient hypothesis at the edge of life: the collapse of facilitation and the switch from facilitation to competition. J Veg Sci 25(2):609-613

Morán-López T, Poyatos R, Llorens P, Sabaté S (2014) Effects of past growth trends and current water use strategies on Scots pine and pubescent oak drought sensitivity. Eur J For Res 133(2):369-382

Nothdurft A, Vospernik S (2018) Climate-sensitive radial increment model of Norway spruce in Tyrol based on a distributed lag model with penalized splines for year-ring time series. Can J For Res 48(8):930-941

Oberhuber W, Stumböck M, Kofler W (1998) Climate-tree-growth relationships of Scots pine stands (Pinus sylvestris L.) exposed to soil dryness. Trees 13(1):19-27

Pretzsch H (2009) Forest dynamics, growth and yield: from measurement to model. Springer, Berlin, p 664

Pretzsch H, Zenner EK (2017) Toward managing mixed-species stands: from parametrization to prescription. For Ecosyst 4:19

Pretzsch H, Block J, Dieler J, Dong PH, Kohnle U, Nagel J, Spellmann $\mathrm{H}$, Zingg A (2010) Comparison between the productivity of pure and mixed stands of Norway spruce and European beech along an ecological gradient. Ann For Sci 67:712 
Pretzsch H, Bielak K, Block J, Bruchwald A, Dieler J, Ehrhart HP, Kohnle U, Nagel J, Spellmann H, Zasada M, Zingg A (2013) Productivity of mixed versus pure stands of oak (Quercus petraea (Matt) Liebl and Quercus robur L.) and European beech (Fagus sylvatica L.) along an ecological gradient. Eur J For Res 132(2):263-280

Pretzsch H, Schuetze G, Uhl E (2013) Resistance of European tree species to drought stress in mixed versus pure forests: evidence of stress release by inter-specific facilitation. Plant Biol 15(3):483-495

Pretzsch H, Biber P, Schütze G, Uhl E, Rötzer T (2014) Forest stand growth dynamics in Central Europe have accelerated since 1870. Nat Commun 5:4967

Pretzsch H, Del Rio M, Ammer C, Avdagic A, Barbeito I, Bielak K, Brazaitis G, Coll L, Dirnberger G, Drössler L, Fabrika M (2015) Growth and yield of mixed versus pure stands of Scots pine (Pinus sylvestris L.) and European beech (Fagus sylvatica L.) analysed along a productivity gradient through Europe. Eur J For Res 134(5):927-947

Pretzsch H, Schütze G, Biber P (2018) Drought can favour the growth of small in relation to tall trees in mature stands of Norway spruce and European beech. For Ecosyst 5:20

Pugnaire FI, Armas C, Maestre FT (2011) Positive plant interactions in the Iberian Southeast: mechanisms, environmental gradients, and ecosystem function. J Arid Environ 75(12):1310-1320

R Core Team (2018) R: a language and environment for statistical computing. R Foundation for Statistical Computing, Vienna, Austria. https://www.R-project.org/

Rajczak J, Pall P, Schär C (2013) Projections of extreme precipitation events in regional climate simulations for Europe and the Alpine Region. J Geophys Res Atmos 118(9):3610-3626

Rigling A, Waldner PO, Forster T, Bräker OU, Pouttu A (2001) Ecological interpretation of tree-ring width and intraannual density fluctuations in Pinus sylvestris on dry sites in the central Alps and Siberia. Can J For Res 31:18-31

Rose L, Leuschner C, Köckemann B, Buschmann H (2009) Are marginal beech (Fagus sylvatica L.) provenances a source for drought tolerant ecotypes? Eur J For Res 128(4):335-343

Rötzer T, Biber P, Moser A, Schäfer C, Pretzsch H (2017) Stem and root diameter growth of European beech and Norway spruce under extreme drought. For Ecol Manag 406:184-195

Schäfer C, Grams TEE, Rötzer T, Feldermann A, Pretzsch H (2017) Drought stress reaction of growth and $\Delta^{13} \mathrm{C}$ in tree rings of European beech and Norway spruce in monospecific versus mixed stands along a precipitation gradient. Forests 8(6):177

Schweingruber FH (1983) Der Jahrring: Standort, Methodik, Zeit und Klima in der Dendrochronologie. Verlag Paul Haupt, Bern und Stuttgart

Soliveres S, Eldridge DJ, Maestre FT, Bowker MA, Tighe M, Escudero A (2011) Microhabitat amelioration and reduced competition among understory plants as drivers of facilitation across environmental gradients: towards a unifying framework. Perspect Plant Ecol 13(4):247-258

Toïgo M, Vallet P, Tuilleras V, Lebourgeois F, Rozenberg P, Perret S, Courbaud B, Perot T (2015) Species mixture increases the effect of drought on tree ring density, but not on ring width, in Quercus petraea-Pinus sylvestris stands. For Ecol Manag 345:73-82

Trouvé R, Bontemps J-D, Collet C, Seynave I, Lebourgeois F (2017) Radial growth resilience of sessile oak after drought is affected by water status, stand density, and social status. Trees 31(2):517-529

Tweedie MCK (1984) An index which distinguishes between some important exponential families. In: Ghosh JK, Roy J (eds) Statistics: applications and new directions. Proceedings of the Indian Statistical Institute. Golden Jubilee international conference. Indian Statistical Institute, Calcutta, pp 579-604

Van der Maaten-Theunissen M, Kahle H-K, Van der Maaten E (2013) Drought sensitivity of Norway spruce is higher than that of silver fir along an altitudinal gradient in southwestern Germany. Ann For Sci 70(2): 185-193

Vitali V, Büntgen U, Bauhus J (2017) Silver fir and Douglas fir are more tolerant to extreme droughts than Norway spruce in southwestern Germany. Glob Change Biol 23(12):5108-5119

Vospernik S, Nothdurft A (2018) Can trees at high elevations compensate for growth reductions at low elevations due to climate warming? Can J For Res 48(6):650-662

Weber P, Bugmann H, Pluess AR, Walthert L, Rigling A (2013) Drought response and changing mean sensitivity of European beech close to the dry distribution limit. Trees 27(1):171-181

White JW, Rassweiler A, Samhouri JF, Stier AC, White C (2014) Ecologists should not use statistical significance tests to interpret simulation model results. Oikos 123(4):385-388

Wood SN (2003) Thin-plate regression splines. J R Stat Soc (B) 65(1):95-114

Wood SN (2004) Stable and efficient multiple smoothing parameter estimation for generalized additive models. J Am Stat Assoc 99(467):673-686

Wood SN (2011) Fast stable restricted maximum likelihood and marginal likelihood estimation of semiparametric generalized linear models. J R Stat Soc (B) 73(1):3-36

Wood SN (2017) Generalized additive models: an introduction with R, 2nd edn. CRC Press, New York, p 496

Publisher's Note Springer Nature remains neutral with regard to jurisdictional claims in published maps and institutional affiliations. 